\title{
First European Symposium on Gastrointestinal Motility
}

The first European Symposium on gastrointestinal motility was held on 7-8 September 1982 in Bologna (Italy) under the chairmanship of Professor Giuseppe Labo (University of Bologna). Organising secretary, M Bortolotti. Review lectures on 'Opioid mechanisms of the gut' (Professor J Hughes, London), and 'the $\bar{\sigma}^{\circ}$ extrinsic innervation of the GI sphincters' (Professor C Roman, Marseille), were given. Sixty-one abstractso (out of 148 submitted) selected for oral or poster presentation are printed below.

1

Alpha-adrenergic control of the interdigestive migrating electrical complex

I ALTAPARMACOV AND M WIENBECK* Sofia, Bulgaria, and Düsseldrof, FR Germany*) As it is still unclear why alpha-adrenergic agents have different effects on the interdigestive migrating electrical complex in duodenum and jejunum and whether they act via a peripheral or a central mechanism, we studied the effect of dihydroergotamine, a predominantly peripheral alpha-adrenergic agent, in 10 subjects without gastrointestinal diseases. For this purpose a 12 -hour recording was made by a tube with four bipolar ring electrodes placed in duodenum and jejunum. Each subject had two doubleblind experiments with the drug and with normal saline as a control.

The alpha-blocker dihydroergotamine applied in a dose of $15 \mu \mathrm{g} / \mathrm{kg}$ intramuscularly reduced the phase 1 in duodenum from $30.5 \pm 4.5 \mathrm{~min}$ ( $\overline{\mathrm{x}} \pm \mathrm{SEM}$ ) to $6.6 \pm 1.4 \mathrm{~min}$ and the phase 2 from $31 \cdot 2 \pm 9 \cdot 5 \mathrm{~min}$ to $11 \cdot 3 \pm 2.7 \mathrm{~min}$ and shortened the phase 3 from $8 \cdot 9 \pm 2 \cdot 6$ to $5 \cdot 7 \pm 0.7 \mathrm{~min}$, increasing simultaneously the number of incidents of phase 3 by $3 \cdot 8 / 1 \mathrm{~h}$ $(\mathrm{p}<0.05$ for all). The decrease of phase 2 and 3 was the same in jejunum, but phase 1 was reduced by $30.9 \%$ less than in the duodenum.

It is concluded that dihydroergotamine increases the motility mainly by increasing the incidence of phase 3 of the interdigestive intestinal motility. It has a similar qualitative but different quantitative effect in duodenum and jejunum. Being a peripheral alpha-blocker, dihydroergotamine suggests a predominant involvement of the peripheral receptors in interdigestive migrating electrical complex control.
2

Somatostatin has a physiological role in the regulation of the migrating motor complex in man

T L PEETERS, G VANTRAPPEN, AND J JANSSENS (Leuven, Belgium) We have shown that pharmacological doses of somatostatin have a striking effect on the migrating motor complex: phase 2 activity is completely abolished, phase 3 activity (also called the activity front) in the intestine is normal but its frequency is tripled. We have now examined the relationship between endogenous somatostatin fluctuations and the migrating motor complex, and the effect of physiological exogenous doses, using an improved radioimmunoassay for somatostatin. Intestinal motor activity was monitored manometrically at three levels. In four volunteers somatostatin was infused in doses of $1 \cdot 2$, $2 \cdot 4$, and $4.8 \mathrm{pM} / \mathrm{kg} / \mathrm{min}$ over three consecutive periods of 90 minutes, causing dose dependent increments in plasma somatostatin levels of $7 \cdot 3,31 \cdot 8$, and $76 \cdot 3$ pM. In all volunteers and for all doses phase 2 activity was completely abolished. The activity front occurred at increased frequency: the mean interval between activity fronts being $39+6 \mathrm{~min}$, compared with a normal period length of 92 minutes $(p<0.01)$. In four other volunteers plasma samples were taken at 10 minute intervals and somatostatin levels correlated to the manometric data. The start of an activity front in the upper duodenum was accompanied by somatostatin peaks. Peak values, taken as the mean of the levels in the sample obtained after the start of an activity front, the preceding sample and the next one, averaged $31 \cdot 7+3 \cdot 7 \mathrm{pM}$ compared with $12 \cdot 2+1 \cdot 8 \mathrm{pM}$ in the remaining period. As motilin is known to induce activity A353 fronts, the effect of motilin infusion on somatostatin levels was also studied. Infu- $\rightarrow$ sion of motilin at a dose of $2.5 \mathrm{pM} / \mathrm{kg} / \mathrm{min}$. in four volunteers elicited an activity front and a somatostatin peak $(23 \cdot 8+4 \cdot 3 \mathrm{pM}$ $\mathrm{p}<0 \cdot 01)$. It is concluded that somatostatinw has a physiological role in the regulation of the migrating motor complex in man and that motilin might elicit activity fronts via somatostatin.

3

Activity front of the migrating motor complex of the human stomach (but not of the small intestine) is motilin dependent

J JANSSENS, G R VANTRAPPEN, T L PEETERS AND J HELLEMANS (Leuven, Belgium) The role of motilin in the regulation of the migrating motor complex remains contro versial. We have shown in man tha? exogenous motilin infusions are able to induce activity fronts and that peaks of endogenous plasma motilin levels occur in relation to the activity front in the upper small intestine. Not every activity front $\mathrm{N}$ however, is accompanied by a motilin peaks and exogenous PP or somatostatin infusions lower plasma motilin levels buñ do not inhibit the occurrence of the activity front (somatostatin even induces intestinak activity fronts). We tested the hypothesis that activity fronts that occur at low plasma motilin levels originate in the small bowe? and not in the stomach. Interdigestive motor activity was recorded manometric ally in five normal subjects after a fast of af least 15 hours. Pressures were measured ind the gastric antrum at four levels $3 \mathrm{~cm}$ aparf and in the upper small bowel at three levels $25 \mathrm{~cm}$ apart. Blood samples were drawr every 10 minutes for RIA of motilin an PP. After two spontaneously occurring 
activity fronts had been recorded, bovine PP was infused intravenously at a rate of $50 \mu \mathrm{g} / \mathrm{h}$. After the third activity front a combination of PP $50 \mu \mathrm{g} / \mathrm{h}$ and 13-norleucine-motilin $30 \mu \mathrm{g} / \mathrm{h}$ was infused until after the next activity front. It was found that $90 \%$ of the spontaneous activity fronts originated in the stomach and were preceded by a motilin peak. During the PP infusion plasma PP levels increased from $29 \mathrm{pmol} / \mathrm{l}$ to $256 \mathrm{pmol} / \mathrm{l}$ and motilin decreased from $42 \mathrm{pmol} / \mathrm{l}$ to $15 \mathrm{pmol} / \mathrm{l}$, and all activity fronts originated in the small bowel. During the combined PP and motilin infusion plasma motilin increased to $330 \mathrm{pmol} / \mathrm{l}$ and all activity fronts again originated in the stomach. It is concluded that motilin has an important role in the regulation of the migrating motor complex activity front in the stomach, not in the small intestine.

4

Inhibition of the human fasting motor complex by prolonged but intermittent mental stress

R M VALORI, A PARNHAM, M PATRICK, A RAIMAN, AND D L WINGATE (London, England) A recent study has shown that prolonged mental stress in recumbent subjects inhibits fasting duodenal motility; however, not all subjects responded to the single stressor applied; and in those who did, adaptation occurred after two hours of stress. Because non-ambulant methods of recording are less physiological and limit the choice of stressors, we have used an ambulant system and applied three different stressors to assess the effects of intermittent stress on small bowel motility.

Fasting duodenal and jejunal motility in healthy volunteers $(n=8)$ was monitored continuously for 33 hours using dual pressure-sensitive ingestible radiotelemetric capsules. Motor complex incidence (continuous 10-12/minute contractile activity, lasting more than two minutes, in at least one sensor) during fasting in seven hours of rest (day 1) was compared with the incidence in a seven hour period (day 2) during which subjects were stressed intermittently by the computer game 'Asteroids' (two hours), driving in heavy traffic (two hours) and a delayed auditory feedback technique (one hour). Stress response was quantified using blood pressure, heart rate, and selfreported visual analogue scales. Positive responses, being taken as a $5 \%$ increase in blood pressure and $10 \%$ in the other variables, were $50 \%$ in systolic blood pressure, $60 \%$ in diastolic, $70 \%$ in heart rate and $75 \%$ in the visual analogue scores. The incidence of motor complexes/hour in day 1 was $0.53 \pm 0.09$ (mean \pm SD) and $0 \cdot 27 \pm 0 \cdot 18$ on day 2 , this difference being significant $(p<0.02$; Wilcoxon's matched pairs signed rank test). The validity of this was emphasised by the similarity of motor complex incidence during the interstress rest periods and during day 1 .

In conclusion, we have shown that the intermittent application of different stressors, as often occurs in everyday life, can alter small bowel motility without inducing adaption, thereby significantly reducing the incidence of motor complexes over prolonged periods of time.

\section{5}

Normalisation of the interdigestive migrating motor complex by the $\mathrm{H}_{2}$ antagonist ranitidine, in patients with idiopathic chronic gastric retention

M BORTOLOTTI, S FOSCHI, A LONGANESI, E TURBA, AND G LABO (Bologna, Italy) In a series of nine patients with 'idiopathic' chronic gastric retention and in six symptomatic controls, we studied the effect of the $\mathrm{H}_{2}$-antagonist ranitidine on the interdigestive gastroduodenal motor activity, by using a 4 lumen probe perfused with an Arndorfer pump, and connected to pressure transducers and a polygraph. After overnight fasting of 14 hours, the recording openings of the probe were positioned under fluoroscopy in the gastric corpus, in the distal antrum, in the first and second portions of the duodenum. Motor activity was recorded for 250 minutes before and for 200 minutes after intravenous administration of ranitidine $50 \mathrm{mg}$.

In controls, phase 3 activity was seen in antrum and duodenum in the basal state (intervals 69-113 minutes), and this was not altered by ranitidine. In the gastric retention patients, four patients had no antral phase 3 activity in the basal state, but had duodenal phase 3 activity at normal intervals; in these, ranitidine restored the antral phase 3 preceding each duodenal phase 3 . In the remaining five patients, no phase 3 activity at all was seen in the basal state, but antral and duodenal phase 3 activity was seen $10-54$ minutes after ranitidine administration.

These observations indicate that $\mathrm{H}_{2}$ antagonist ranitidine does not modify the normal gastroduodenal interdigestive migrating motor complex, but is able to restore gastric interdigestive migrating motor complex phase 3 in patients with gastric retention. Probably, this drug does not act on the regulating mechanism of interdigestive migrating motor complex, but, in chronic gastroparesis, it removes inhibitory mechanisms on the interdigestive migrating motor complex phase 3 involving $\mathrm{H}_{2}$ receptors.

\section{6}

Continuous enteral nutrition in dogs: influence of the caloric load on the intestinal migrating myoelectric complex

F CRENNER, J C SCHANG, G FELDER, AND J F GRENIER (Strasbourg, France) We have shown previously that continuous enteral nutrition induces a temporary inhibition of the intestinal migrating myoelectric complex.

The aim of the present work was to investigate the effects of different caloric flows of continuous enteral perfusion on the migrating myoelectric complex. Five dogs (15-18 kg) were prepared for chronic electromyographic recordings with 10 extracellular $\mathrm{AgAgCl}$ electrodes serosally sewn on the duodenum, the jejunum, and the ileum. A drip-feeding tube was placed into the duodenum. After recovery, control tracings were made for two days during fasting. Then, continuous enteral perfusion was started just after the occurrence of a phase 3 of the migrating myoelectric complex on the duodenum; the liquid flow through the duodenal tube was $2 \mathrm{ml} / \mathrm{min}$. Four experiments with different caloric loads $(1000,1500,2000$, and 3000 $\mathrm{kcal} /$ day) were performed in each dog; experiments on the same dog were separated by 10 days of normal nutrition, followed by a renewed control tracing made for two days during fasting. The perfused mixture contained $55 \%$ carbohydrates, $27 \%$ fat, and $18 \%$ peptides. The parameters studied were: (1) the time interval $\mathrm{T} 1$ between the beginning of the perfusion and the occurrence of a phase 3 on the duodenum, this phase 3 being taken into account only if it propagates from the duodenum to the terminal ileum; (2) the period $\mathrm{T} 2$ taken by the recurrence interval of the migrating myoelectric complex to come back to its control value.

During the control period, migrating myoelectric complexes recurred at $95 \pm 15$ (mean \pm SEM) intervals. During continuous nutrition, there was a fed pattern during $\mathrm{T} 1$, which increased from $100 \pm 50$ minutes with $1000 \mathrm{kcal} /$ day to $19 \pm 4$ hours 
with $2000 \mathrm{kcal} / \mathrm{day}$ and $64 \pm 15$ hours with $3000 \mathrm{kcal} /$ day. At the end of T1, migrating myoelectric complexes recurred at long and irregular intervals, and many episodes of 'phase 3-like' activity were seen in the duodenum and jejunum which did not propagate distally. Values for $\mathrm{T} 2$ increased with caloric load, being $13 \pm 4.24 \pm 0$. $72 \pm 19$, and $170 \pm 43$ hours respectively for the $1000,1500,200(0)$, and $3(x)(\mathrm{kcal} / \mathrm{dal}$. loads. When perfusion was continued for seven days after the end of 12 . there was no significant change in pattern.

These results showed that: (1) the intestinal electromyographic recordings can show a fasting pattern in spite of the presence of nutrients in the lumen; (2) the mechanisms inducing the inhibition of the migrating myoelectric complex become ineffective after a time period depending on the caloric load of the continuous enteral perfusion.

\section{7}

Gastrin delays emptying of liquids in the rat

C SCARPIGNATO, M G GIRONE, AND G BERTACCINI (Parma, Italy) Although it is generally assumed that gastrin delays gastric emptying, the role of endogenous acid in the motor action of this peptide has not been definitely elucidated. An approach to this problem derived from experiments performed in patients affected by pernicious anaemia, which seem to indicate that pentagastrin affects gastric emptying independently of an action on gastric acid output. In the present study, we evaluated, in conscious rats, the effect of a synthetic peptide (human gastrin I, Research Plus, Bayome, NJ) on gastric emptying of a phenol red meal. The peptide, dissolved in saline, was injected intraperitoneally five minutes before the meal. The animals were killed at various time intervals for the evaluation of the kinetics; a fixed time (20 minutes) was chosen for the study of dose-response relationships. Gastrin delayed the emptying of liquids in a dose-dependent fashion (10-100 $\mu \mathrm{g} / \mathrm{kg})$, but did not modify the first order kinetics. The emptying half-time in gastrin $(80 \mu \mathrm{g} / \mathrm{kg})$-treated rats was significantly higher than in controls $(72 \cdot 7 \pm 27 \cdot 2$ minutes vs $15 \cdot 3 \pm 6 \cdot 2$ minutes). Neutralisation of acid by intragastric sodium bicarbonate or pretreatment of animals with $\mathrm{H}_{2}$-blockers (cimetidine or oxmetidine 20 and $4 \mathrm{mg} / \mathrm{kg}$ respectively) significantly decreased but not completely abolished the delay in emptying induced by the heptadecapeptide. These data, in accordance with the results obtained in dogs by Valenzuela and Grossman, suggest that, in the rat, the effect of gastrin on gastric emptying is mediated at least partially by acid secretion.

\section{8}

Smooth muscle motilin receptors in rabbit stomach and duodenum

$\checkmark$ BORMANS, $T$ L PEETERS, AND $G$ R VANTRAPPEN (Leuven, Belgium) Motilin influences gastrointestinal motility and is able to initiate interdigestive activity fronts in the gastric area in man and in dogs. From studies of the effect of motilin on isolated rabbit ileal smooth muscle it has been concluded that motilin has a direct effect on the smooth muscle cell. We therefore studied the presence of motilin receptors on subcellular preparations of antral and duodenal smooth muscle tissue in rabbits.

Smooth muscle tissue was homogenised in $0.25 \mathrm{mM}$ sucrose $0.05 \mathrm{M}$ Tris- $\mathrm{HCl}$ buffer (pH 7.4) and fractionated by differential centrifugation at $270 \mathrm{~g}, 30000 \mathrm{~g}$, and $60000 \mathrm{~g}$. Fractions were biochemically characterised by determination of ATPase, 5'-nucleotidase, cytochrome-c-oxidase and total protein. Motilin-receptor binding was studied by incubating the different fractions with $30000 \mathrm{cpm}$ (40 fmol) I-125 porcine-motilin in $0.05 \mathrm{M}$ Tris- $\mathrm{HCl}$ buffer (pH 7.4) containing $1 \% \mathrm{BSA}$ at $30^{\circ} \mathrm{C}$ for 50 minutes. Membrane bound motilin was separated by centrifugation at $60000 \mathrm{~g}$. Non-specific binding was determined by the addition of an excess of unlabelled motilin.

Specific binding was observed in the plasma membrane fraction $(60000 \mathrm{~g}$ pellet) characterised by the presence of a high relative specific activity of $5^{\prime}$ nucleotidase and ouabain sensitive $\mathrm{Na}-\mathrm{K}$ ATP-ase, and was almost undetectable in all other fractions. Specific binding was temperature and protein concentration dependent and was competitively displaced by unlabelled motilin, but not by glucagon, gastrin, and substance-P. Under similar conditions plasma membrane preparations of antrum and upper duodenum bound respectively 3.01 and $0.51 \mathrm{fmol} / \mathrm{mg}$ protein.

This is the first report of motilin smooth muscle receptors. From our studies it can be concluded that motilin can interact directly with smooth muscle cells. The

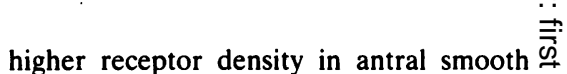
muscle tissue could explain the higher $\bar{C}$ sensitivity of the antrum for motilin.

9

Effect of caerulein on motor activity of the sphincter of Oddi

v GATTI, E DE MASI, E CORAZZIARI, B FONTANA, F I HABIB, AND A TORSOLI (Roma, Italy) Cholecystokinin (CCK) analogues $\stackrel{\vec{\sim}}{\vec{\sim}}$ may have opposite effects on the sphincter of Oddi in different animal species. With ERCP manometry it is now possible to investigate the sphincter of Oddi in $\omega$ humans. Recently CCK-octapeptide 음 (CCK-OP) has been shown to inhibit the sphincter of Oddi basal pressure and phasic $D$ contractions. In this study the effect of another CCK-analogue, caerulein (Ceruletide, Farmitalia, Milano, Italy) on $\mathscr{\bullet}$ the sphincter of Oddi pressure activity has $\omega$ been investigated. Six patients undergoing ERCP examination for suspected biliary gallstones were investigated (at ERCP: three apparently normal and three ductal $\overline{\bar{O}}$ stones). Before endoscopy, patients were 을 sedated with diazepam (10-20 mg intra- \& venously). After ERCP examination, a $\overrightarrow{\bar{B}}$ miniaturised triple lumen catheter (external diameter: $1.7 \mathrm{~mm}$; lumen: internal diameter: $0.5 \mathrm{~mm}$; Arndorfer, USA) with distally recording side-holes located $2 \mathrm{~mm}$ apart was passed into the common bile duct and checked fluoroscopically. Duodenal intraluminal pressure 3 was obtained by a single lumen catheter taped to the endoscope. Each lumer was continuously infused with bubble-free water by a hydraulic-capillary infusion 음 system. After positioning, under endo- $D$ scopic control, the catheter recording holes in the sphincter of Oddi segment at $8,6, \vec{N}$ and $4 \mathrm{~mm}$ from the papillary orifice, $\sigma$ intraluminal pressures were recorded for a $N$ 90 second period after saline intravenous $N$ bolus and for a six minute period after $\omega$ caerulein $(1.0 \mathrm{ng} / \mathrm{kg} \mathrm{bw})$ intravenous bolus administration.

The intravenous pulse dose of caerulein $\overparen{\mathscr{D}}$ did not cause any intraduodenal pressure $\stackrel{\mathscr{S}}{+}$ variation, but it induced an inhibition of $T$ sphincter of Oddi basal pressure (control: $\bar{O}$ $15 \cdot 1 \pm 5 \cdot 1 \mathrm{~mm} \mathrm{Hg}$ ), which was seen four $\mathbb{D}$ minutes after injection $(10.4 \pm 4.0 \mathrm{~mm} \mathrm{Hg}) \stackrel{\frac{}{\mathbb{D}}}{\circ}$ and still present at six minutes $(10 \cdot 2 \pm 4 \cdot 7)$. 으 Phasic contractions were diminished in frequency, amplitude, and duration one? minute after injection and completely음 abolished at two minutes. Diminished con- 
tractions were seen four minutes after length. Computer analysis of the gamma injection, but had not returned to normal camera data confirmed this change and at six minutes (frequency, $1 \cdot 3 \pm 0 \cdot 4 / \mathrm{min} v s$ showed a resting volume of $24 \mathrm{ml}$ $2 \cdot 8 \pm 0.7 / \mathrm{min}$ basal; amplitude, $42.5 \pm 18.9$ increasing to 4()$\cdot 5 \mathrm{ml}$ during vasopressin $\mathrm{mm} \mathrm{Hg}$ vs $71.8 \pm 11.7 \mathrm{~mm} \mathrm{Hg}$ basal; infusion. Rapid sequential imaging duration, $3 \cdot 7 \pm 1 \cdot 3$ seconds $v s \quad 5 \cdot 2 \pm 0.6$ revealed abrupt cessation of jejunal motor seconds basal).

In conclusion, data from this study indicate that, as with CCK-OP, caerulein causes a significant inhibition of sphincter of Oddi motor activity and therefore suggest that CCK may have a role in the regulation of the sphincter of Oda" . otor activity in humans.

10

Changes in intestinal volume, motility, and electrical activity in response to intravenous vasopressin

A Mitchell, J COLLIN, D MACEY, AND $R 11$

youNG (Oxford, UK) In clinical practice, Effects of prostaglandins on the motility of vasopressin produces intestinal colic and the isolated circular musculature of the cat urgency of defaecation. Previous work has colon

suggested an increase in intestinal absorption and the aim of this study is to assess the effects of vasopressin on jejunal volume, motility, and electrical activity.

In three dogs a segment of jejunum was isolated with proximal and distal stomata on the abdominal wall. Electrodes were sutured to the serosal surface of the segment. The dogs were fed before each experiment and a solution containing $50 \cdot 7$ $\mathrm{g} / \mathrm{l}$ mannitol was infused at $2.9 \mathrm{ml} / \mathrm{min}$ into the proximal stoma. This non-toxic solution shows zero net absorption (absorption clamp) and does not alter intestinal electrical activity. Effluent was collected from the distal stoma at five minute intervals for three hours. During the second hour vasopressin $0.02 \mathrm{U} / \mathrm{kg} / \mathrm{min}$ was infused intravenously. Effluent volumes were measured. Electrical recordings were made from the jejunum throughout the experiment. Six experiments were performed on each dog. The addition of Tc-99m labelled tin colloid to the perfusion solution allowed gamma camera imaging of the segment and subsequent computer analysis of changes in volume and motility.

The results showed that during intravenous vasopressin infusion, fast wave electrical activity was abolished, slow waves were disrupted and transit time increased $(4.4 \pm 1 \cdot 3$ to $19.9 \pm 2.7 \mathrm{~min})$ $(\mathrm{p}<0 \cdot 001)$. Effluent volume fell $(14 \cdot 5 \pm 0 \cdot 2$ to $6.3 \pm 1.2 \mathrm{ml} / 5 \mathrm{~min})(\mathrm{p}<0.001)$ and the deficit was recovered when vasopressin infusion ceased, showing an intestinal volume increase of $0.22 \mathrm{ml} / \mathrm{cm}$ of intestinal activity with dilatation of the segment, beginning proximally when vasopressin was infused. Motor and electrical activity recovered in parallel when vasopression was withdrawn.

It was concluded that changes in intestinal volume can be simply and accurately measured while intestinal motility can be monitored by computerised gamma camera imaging. We have shown that vasopressin produces jejunal atony with abolition of fast wave activity and a $67 \%$ increase in small intestinal volume.

11

TH SPERLING AND M WIENBECK (Düsseldorf, FR Germany) Prostaglandins (PG) occur throughout the gut. They are augmented in ulcerative colitis, but their role in the regulation of colonic motility is still incompletely understood. Therefore, we studied the effects of $\mathrm{PGF}_{2 \alpha}, \mathrm{PGE}_{2}$, and the PG-receptor antagonist HR 546 (8ethoxycarbamyl-10,11-dihydroxy-Aprostaglandin) on spontaneously active and electrically stimulated colon musculature over a wide range of drug concentrations. Strips of circular muscle of the cat colon $(1.5 \times 10 \mathrm{~mm})$ were mounted in a perspex chamber and superfused with gassed Krebs' solution at $38^{\circ} \mathrm{C}$. Contractile activity was recorded with straingauge transducers, electrical activity with $\mathrm{Ag}$ $\mathrm{AgCl}$ glass pore electrodes. The strips were electrically stimulated five times/minute corresponding approximately to the slowwave frequency. $\mathrm{PGF}_{2 \alpha}$ increased the spontaneous activity $22 \cdot 1 \pm 6 \cdot 5$ (SEM) times and the stimulated activity $27 \cdot 0 \pm 7 \cdot 2$ times at $6 \times 10^{-7} \mathrm{M}, \mathrm{ED}_{50}$ was $4.2 \times 10^{-9} \mathrm{M}$. $\mathrm{PGE}_{2}$ raised muscle activity $8 \cdot 6 \pm 1 \cdot 4$ times at $1.3 \times 10^{-5} \mathrm{M}, \mathrm{ED}_{50}$ was $2 \times 10^{-7} \mathrm{M}$. The dose-response curve of $\mathrm{PGE}_{2}$ was shifted $1.8 \log$ units to the right compared with that of $\mathrm{PGF}_{2 \alpha}$. HR 546 proved to be a non-competitive antagonist; a concentration of $10^{-8} \mathrm{M}$ shifted the dose-response curve to the right by $0.7 \log$ units and enhanced contractile activity at PG concentrations of $10^{-10}$ and $10^{-11} \mathrm{M}$.

We concluded that prostaglandins $F_{2 \alpha}$ and $E_{2}$ stimulate motor activity of the circular cat colon musculature already at low concentrations. $\mathrm{PGF}_{2 \alpha}$ is more effective than $\mathrm{PGE}_{2}$ and may be involved in the motility disturbances seen in inflammatory bowel disease.

\section{2}

Indomethacin enhances gastric antral motility by inhibition of prostaglandin $E_{2}$ in beagle dogs

K BECH, C P HOVENDAL, K BUKHAVE, AND J RASK-MADSEN (Odense and Herlev, Denmark) In vitro studies have recently suggested that prostaglandins (PG) particularly of the E series - may act as local regulators of gastric antral motility. As in vivo studies have shown symmetrical peaks in gastric $\mathrm{PGE}_{2}$ output preceded by increased antral motility during sustained $50 \%$ maximal stimulation by pentagastrin, experiments were performed to investigate the interrelationship, if any, between motility indices and $\mathrm{PGE}_{2}$ levels in gastric juice.

Beagle dogs $(n=7)$ with gastric fistula were used. Antral motility was measured by Millar micro-tip transducers and expressed as mean amplitude (MA). Gastric juice was collected in 10 minute periods for 210 minutes during continuous infusion of pentagastrin $(1 \mu \mathrm{g} / \mathrm{kg} / \mathrm{h})$ \pm indomethacin $(3 \mathrm{mg} / \mathrm{kg}+1 \mathrm{mg} / \mathrm{kg} / \mathrm{h}$; plasma concentrations $=3 \cdot 4-7 \cdot 4 \mu \mathrm{g} / \mathrm{ml}$ ) or bethanechol $(80 \mu \mathrm{g} / \mathrm{kg} / \mathrm{h})$. Samples of gastric juice were immediately titrated to $\mathrm{pH} 7.0$ and immunoreactive $\mathrm{PGE}_{2}$ was determined by a method validated by gas chromatography-mass spectrometry.

During pentagastrin stimulation the motility pattern was digestive with a median MA $=87.2$ (range 59.2-149.9) and median $\mathrm{PGE}_{2}$ levels $=1.99 \mathrm{ng} / \mathrm{ml}(0 \cdot 11-$ 3.05). Continuous bethanechol infusion produced a pattern with significantly $(\mathrm{p}<0.05)$ higher MA - namely, 194.4 $(68.6-433.7)$ and insignificantly $(\mathrm{p}<0.2)$ lower $\mathrm{PGE}_{2}$ levels - namely, $1.49 \mathrm{ng} / \mathrm{ml}$ (0.33-2.05). Administration of indomethacin during pentagastrin infusion increased MA to $399.6 \quad(132.0-610.9$; $\mathrm{p}<0.05)$ and reduced $\mathrm{PGE}_{2}$ levels to 0.29 $\mathrm{ng} / \mathrm{ml}(0 \cdot 11-1 \cdot 39 ; \mathrm{p}<0 \cdot 05)$.

The demonstration of a significant inverse linear relationship between $\mathrm{PGE}_{2}$ concentrations in gastric juice and antral motility suggests that $\mathrm{PGE}_{2}$ act as a physiological feedback inhibitor of gastric antral motility. 
13

Wet swallows stimulate abnormal oesophageal contractions in patients with oesophageal motility disorders

H D JANISCH AND V F ECKARDT (Mainz, FR Germany) Previous studies in normal persons comparing the peristaltic response with dry and wet swallows have shown that wet swallows increase the amplitude and duration of oesophageal contractions and lead to a greater prevalence of peristalsis. This study investigates whether a similar phenomenon can be observed in patients with oesophageal motility disorders.

Oesophageal manometry using a high fidelity low compliance system was performed in eight healthy volunteers and in 24 patients with oesophageal motility disorders (achalasia, 10; diffuse oesophageal spasm, 7; intermediate, 7). Oesophageal contraction responses to 10 dry, 10 wet, and 10 wet swallows after pentagastrin were recorded 5 and $10 \mathrm{~cm}$ proximal to the lower oesophageal sphincter.

These results show that in the distal oesophagus, wet swallows increased contraction amplitudes in patients (dry swallows: $28.4 \pm 5.6 \mathrm{~mm} \mathrm{Hg}$, mean $\pm 1 \mathrm{SE}$ wet swallows: $35.0 \pm 6.3 \mathrm{~mm} \mathrm{Hg}$ ) and in controls (dry swallows: $55.6 \pm 6.6 \mathrm{~mm} \mathrm{Hg}$; wet swallows: $81 \cdot 4 \pm 13.5 \mathrm{~mm} \mathrm{Hg}$ ). Patients, but not controls, had longer durations of oesophageal contractions after wet swallows compared with dry swallows. Similarly, the incidence of repetitive contractions increased during wet swallows in patients (dry swallows: $31 \cdot 2 \pm 2 \cdot 6 \%$; wet swallows: $67.5 \pm 5.9 \%$ ), but not in controls (dry swallows: $2 \cdot 5 \pm 1.6 \%$; wet swallows: $6.2 \pm 1.9 \%)(p<0.001)$. The administration of pentagastrin in patients led to a further increase in duration and amplitude of oesophageal contractions, but the prevalence of abnormal contractions remained unaltered.

It is concluded that (1) a wet swallow is a more sensitive discriminator than a dry swallow for showing abnormal oesophageal contractions and (2) the changes observed during wet swallows are possibly related to an increase in oesophageal baseline pressure in patients with oesophageal motility disorders.

14

Oesophageal functions tests in patients with sliding hiatus hernia and symptoms of gastro-oesophageal reflux s bOESby (Odense, Denmark) The aim of the present study has been to assess the clinical use of oesophageal function tests in patients with sliding hiatus hernia and symptoms of gastro-oesophageal reflux.

One hundred patients, 50 women and 50 men (aged 28-82 years; mean 58.7), with radiologically verified sliding hiatus hernia and heartburn and/or regurgitation underwent intraluminal oesophageal manometry, acid clearing test and 12-hour continuous oesophageal pH-recording (acid reflux measurement). The results are compared with those obtained in normal subjects.

The $\mathrm{pH}$-recordings were analysed automatically for the duration of $\mathrm{pH} \leqslant 2 \cdot 3,3,4$, and 5 as percentage of the total time of recording; further, integration of the curve below $\mathrm{pH} 3,4$, and 5 was carried out.

The results show that basal gastrooesophageal sphincter pressure (B-LOSP) was lower in patients (median $6 \mathrm{~mm} \mathrm{Hg}$, range 1-18) than in normal subjects (median $15 \mathrm{~mm} \mathrm{Hg}$, range $8-24$ ) $(p<0.0001)$. Seventy-four out of 100 patients had B-LOSP lower than normal, while the remainder had normal pressures. Acid clearing was prolonged in patients $(p<0.01)$. Thirty-three out of $75(44 \%)$ patients had prolonged clearing. Duration of $\mathrm{pH} \leqslant 2.3$ (median $0.53 \% ; 0-35.19 \%$ ), $\mathrm{pH} \leqslant 3$ (median $2 \cdot 19 \% ; 0-60 \cdot 17 \%$ ), $\mathrm{pH} \leqslant 4$ (median 5.8\%; 0-85\%), $\mathrm{pH} \leqslant 5$ (median $14.34 \%$; 0-96.32\%) were higher than normal values $(\mathrm{p}<0.001)$. Using $\mathrm{pH} \leqslant 2 \cdot 3$ : $37 / 79(46.8 \%) ; \mathrm{pH} \leqslant 3: 49 / 79(62 \%) ; \mathrm{pH}$ $\leqslant 4: 51 / 79(64.6 \%) ; \mathrm{pH} \leqslant 5: 53 / 79(73.6 \%)$ of patients were above the upper limit of normal. Using results from the integration of the curves below pH 3: $29 / 72$ (40\%); below pH 4: 46/72 (63.9\%); below pH 5: $(73.6 \%)$ were above the upper limit of normal. Comparing these results with the normal values, of the $\mathrm{pH}$-recording significant higher acid reflux was found in patients $(\mathrm{p}<0.001)$.

It is concluded that the best separation between normal subjects and patients is obtained using B-LOSP or integration of $\mathrm{pH}$-curve below $\mathrm{pH} 5$. Because of the marked overlap between results in normal subjects and patients, the tests seem of little value in the assessment of the single patient with typical symptoms.

\section{5}

Gastro-oesophageal reflux in infants and children: manometrical analysis. Possible relation with chronic broncho-pulmonary disease
G CARGILL, J M GOUTET, J VARGAS, H BOUtignon, AND J NAVARro (Paris, France) One hundred and fifty-six infants and children with symptoms of gastrooesophageal reflux were explored by oesophageal manometry associated with external pharyngeal electromyography. Particular interest was taken in the study of the pressure and motor activity of both superior and inferior oesophageal sphincters. Distinction was made between: (a) sixty patients with chronic bronchopulmonary disease; (b) presence or not of iterative relaxations (defined as relaxations of the lower oesophageal sphincter out of the normal peristaltic sequence); and (c) the influence of metoclopramide. The statistical analysis of the results revealed that the mean pressure of the upper oesophageal sphincter is significantly lower $(\alpha<0.0001)$ in patients presenting with chronic broncho-pulmonary disease, while there is no correlation with other parameters; and that gastro-oesophageal reflux without iterative relaxations is characterised by low lower oesophageal sphincter pressure $\left(x=9.85 \mathrm{~cm} \mathrm{H}_{2} \mathrm{O}\right.$ for $\mathrm{N}=25 \pm 9.4 \mathrm{~cm} \mathrm{H}_{2} \mathrm{O}$ ). Two main conclusions were obtained from the study of the effect of medical therapy: (a) the therapy does not influence the presence of iterative relaxations. A significant increase in lower oesophageal sphincter pressure was found in the group without iterative relaxation while it was poorly augmented $(\alpha<0.02)$ in the group with iterative relaxation and (b) the upper oesophageal sphincter pressure is not modified by treatment.

In conclusion this study shows the interest of identification of gastrooesophageal reflux with iterative relaxation and the very significant correlation of low upper oesophageal sphincter pressure and respiratory risks.

16 Radiotelemetric continuous oesophageal pH monitoring in infants

D URBANO, M ABELA, G SANGES, $S \stackrel{\mathscr{C}}{(}$ TERRANOVA, E GIANNAZZO, AND A DI BENEDETTO (Catania, Italy) Twenty-four hour monitoring has been shown to be the most valuable diagnostic procedure to $\mathbb{D}$ determine quantitatively gastro- $\overrightarrow{\mathbb{D}}$ oesophageal reflux. The high incidence of $\frac{2}{\sigma}$ gastro-oesophageal reflux in infants in combination with their inability to o verbalise the symptoms, makes the continuous monitoring of the distal 
oesophageal $\mathrm{pH}$ value an essential tool for separating physiological from pathological gastro-oesophageal reflux. A radiotelemetric technique was therefore used for monitoring 24 hour distal oesophageal $\mathrm{pH}$ in 20 infants, under non-restricted conditions, electrical connections being avoided. The diagnostic reliability of the method was assessed by means of its application to the examination of 10 infants (3-40 days old) showing clinical symptoms of gastro-oesophageal reflux (group 1). Ten infants (5-35 days old) showing no clinical symptoms of gastro-oesophageal reflux were used as controls (group 2). The method allowed evaluation of the parameters that are established by currently adopted criteria. Assignment of the patients to the three following groups is proposed on the basis of total reflux time data: (a) pathological: TRT $>40 \%$ (three patients of group 1); (b) intermediate: TRT $20-40 \%$ (six patients of group 1); (c) normal: TRT $<20 \%$ (10 patients of group 2 and one patient of group 1). The monitoring technique adopted avoided undesirable postural and psychological effects on the amount of reflux episodes. The method also showed its applicability and usefulness in the evaluation of results in the course of medical and/or surgical therapy.

\section{7}

Comparison of the effects of classical and selective antimuscarinic drugs on oesophageal motility

B H JAUP, H ABRAHAMSSON, AND G DOTEVALL (Göteborg, Sweden) In order to evaluate the antimuscarinic selectivity of pirenzepine, its effects on oesophageal smooth muscle function was compared with that of atropine and 1-hyoscyamine in a placebocontrolled study. In three series, each in seven healthy volunteers, oesophageal peristalsis was registrated after liquid swallows, using electronic pressure transducers at $10 \mathrm{~cm}$ above lower oesophageal sphincter pressure. In the first series each subject underwent three experiments: control, after $0.5 \mathrm{mg}$ atropine and after 10 $\mathrm{mg}$ pirenzepine intravenously. The duration of the experiments was 90 minutes. In the second series the same volunteers were premedicated with either $50 \mathrm{mg}$ pirenzepine twice daily, $0.6 \mathrm{mg}$ 1-hyoscyamine twice daily, or placebo perorally during four days. The drug doses are considered to have equal potency in the inhibition of gastric acid secretion. The experiments were carried out two hours after the last drug administration. In the third series, the volunteers were, for four days, premedicated with pirenzepine 25 $\mathrm{mg}, 50 \mathrm{mg}$ twice daily, $50 \mathrm{mg}$ three times a day, or placebo perorally. Experiments were then carried out as described above. Serum levels of atropine, 1-hyoscyamine, and pirenzepine were measured by a RIA method during all experiments.

Results show that both atropine and pirenzepine intravenously decreased oesophageal peristaltic amplitudes significantly. Inhibition by pirenzepine, however, was significantly less between 20 to 90 minutes. In the second series the peristaltic amplitudes were decreased by $50 \%$ after 1-hyoscyamine $(p<0.01)$ and by $20 \%$ after pirenzepine (ns). For the different doses of pirenzepine a dose-response relationship was found similar to that in previous studies with modified sham-feeding.

In conclusion, the present results are found to be in agreement with a concept of different subclasses of muscarinic receptors, where pirenzepine shows a lower affinity to muscarinic receptors of smooth muscles than atropine of 1 hyoscyamine.

\section{8}

Outpatient 24 hour oesophageal pH monitoring with an original apparatus

S MATTIOLI, S FOSCHI, V PILOTTI, R B BRAGAGLIA, B F SANTERAMO, R ZANNOLI, G GOZZETTI, AND G LABÒ (Bologna, Italy) An inexpensive, reliable, 24 hour outpatient oesophageal $\mathrm{pH}$ monitoring apparatus is described. The $\mathrm{pH}$-electrode is connected to a mini $\mathrm{pH}$-meter; the electrical signal, modulated in frequency, is recorded on a common portable cassette tape recorder. To obtain sufficient recording autonomy, an electronic timer programmed for $15 \mathrm{sec} / \mathrm{min}$, was applied. This recorded signal, fed to another standard recorder, was demodulated and put on paper. The reliability of this method has been already verified by the continuous parallel monitoring, using a low-speed paper recorder, of 16 inpatients, some with reflux oesophagitis. The calculated percent reflux duration was almost identical with both methods while total number of refluxes $(\mathrm{pH}<4)$ revealed that $5 \%$ had escaped detection by the non-continuous method. If the $\geqslant 5$ minute refluxes were considered, however, the correspondence was $100 \%$, as the only unregistered reflux was that which occurred and was cleared within the 45 second 'blind' period. It is necessary that someone changes the cassette once during the night.

We tested seven volunteers and 11 patients with reflux oesophagitis diagnosed with endoscopy, histology, and radiology. These are the average values of the parameters calculated: number of reflux episodes per hour; in the upright position (UP) 1.9 (nv 0.61), in the supine position (SP) 1.5 (nv 0.8). Reflux episodes $\geqslant 5$ minutes duration: number per hour, UP 0.51 (nv 0.21), SP 0.47 (nv 0.1); percent average duration on UP time $24 \cdot 2$ (nv 0.5 ) and on SP time 27.3 (nv $0 \cdot 15$ ). In conclusion, this method of 24 hour home oesophageal $\mathrm{pH}$-monitoring is accurate, and reliable, and costs 25 times less than any Holter based method, so this apparatus can be afforded by any medical and surgical unit.

19

Motility of distal oesophagus and gastrooesophageal reflux

E CORAZZIARI, I BONTEMPO, F ANZINI, AND A TORSOL (Roma, Italy) The relationship between intraoesophageal $\mathrm{pH}$ value and motor activity of the lower oesophageal body and sphincter was investigated by simultaneous evaluation of intraluminal pressure and $\mathrm{pH}$ in 13 patients $(10$ men, three women; age $44 \pm 19$ years; $M \pm S D$ ) complaining of heartburn and regurgitation. In each patient a constantly perfused triple lumen catheter was passed into the gastric fundus and $200 \mathrm{ml} \mathrm{HCl} 0 \cdot 1 \mathrm{~N}$ were instilled into the stomach; the catheter was then withdrawn and randomly positioned for two consecutive periods of 20 minutes at the level of (a) the oesophageal body and (b) the lower oesophageal sphincter and oesophageal body. $\mathrm{A} \mathrm{pH}$ glass electrode was positioned $5 \mathrm{~cm}$ proximal to the lower oesophageal sphincter. A belt pneumograph around the neck recorded swallows. The study was performed after an overnight fast in patients quietly resting in the supine position. The sudden fall of the intraoesophageal $\mathrm{pH}$ of at least 1.0 unit below 5.0 was regarded as evidence of gastro-oesophageal reflux. One hundred and thirty-one episodes of gastrooesophageal reflux were recorded: 118 $(90 \cdot 1 \%)$ were preceded by a swallow (1-12 seconds), 13 reflux episodes $(9.9 \%)$ were not preceded by a swallow. Gastrooesophageal refluxes preceded by a swallow were accompanied by an equal number of normal and abnormal primary peristaltic sequences and, while recording 
at level of the lower oesophageal sphincter, occurred during inhibition of the sphincter. Frequency of abnormal primary peristalsis increased $(\mathrm{p}<0.01)$ during periods of low intraluminal $\mathrm{pH}(<5 \cdot 0)$. An increase of at least $0.5 \mathrm{U}$ in intraluminal $\mathrm{pH}$ occurred with $45.2 \%$ of normal primary peristalsis, $29.3 \%$ of abnormal primary peristalsis, $4.3 \%$ of secondary peristalsis, $3.5 \%$ of non-peristaltic contractions.

It is concluded that, in patients with symptoms of reflux oesophagitis, gastrooesophageal reflux appears to be related to swallow-induced lower oesophageal sphincter inhibition and not related to abnormal motor activity of the distal oesophageal body where. an increased frequency of abnormal primary peristalsis appears to occur during low intraluminal $\mathrm{pH}$. Primary peristalsis appears to be the most important mechanism of oesophageal clearing.

20

Effect of intragastric ethanol on upper digestive and pancreatic secretion in man

P DEMOL, M V SINGER, J HOTZ, U HOFFMANN, AND H GOEBELL (Essen, FR Germany) In humans and dogs, exocrine pancreatic secretion into the duodenum during fasting is cyclical and related to intestinal motility. In dogs, intraduodenal infusion of ethanol disrupts interdigestive motor activity. In humans, intraduodenal ethanol stimulates pancreatic bicarbonate output. As yet the action of intragastric ethanol on exocrine pancreatic secretion in relation to interdigestive motor activity has not been studied in humans.

After an overnight fast healthy volunteers swallowed a gastric tube and a duodenal tube with four polyethylene catheters. This duodenal catheter assembly was used to record duodenal pressures and measure pancreatic secretion of amylase and bicarbonate , based on the recovery of a constantly perfused marker. The intragastric instillation of the test solutions was always started during phase 1,10 minutes after the end of phase 3 of the interdigestive motor activity. On different days either $100 \mathrm{ml}$ of ethanol $(40 \% \mathrm{v} / \mathrm{v})$ or dextrose $(53 \mathrm{~g} \% .3100 \mathrm{mOsm} / \mathrm{kg}$, isocaloric with ethanol) were given within five minutes. In control experiments either nothing or $100 \mathrm{ml}$ of distilled water was given. Duodenal juice samples were collected every 15 minutes for at least two hours and duodenal motility was recorded until the reappearance of a new phase 3 .
The results showed that of the meals given only dextrose significantly $(p<0 \cdot 05)$ prolonged the interval between interdigestive motor activity phase 3 activity $(189 \pm 16 \min , \mathrm{n}=8)$ compared with water $(130 \pm 17 \mathrm{~min}, \mathrm{n}=6)$ and control studies

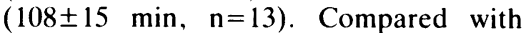
controls, ethanol $(n=9)$ and dextrose, but not water, increased duodenal bicarbonate output seven to 16 -fold respectively $(1400 \pm 700$ and $3100 \pm 1000 \mu \mathrm{mol} / \mathrm{h}$ vs $200 \pm 100 \mu \mathrm{mol} / \mathrm{h} ; \mathrm{p}<0.05)$. The amylase response to dextrose $(28 \pm 4 \mathrm{KU} / \mathrm{h})$ was significantly $(p<0.05)$ greater than that in control experiments $(10 \pm 1 \mathrm{KU} / \mathrm{h})$, but was not significantly greater than the amylase response to ethanol $(21 \pm 2 \mathrm{KU} / \mathrm{h})$.

It is concluded that in humans, intragastric instillation of ethanol in a concentration present in whisky and in an amount that is consumed in ordinary social drinking has a small secretin-like effect on the pancreas and does not alter the upper intestinal motor activity.

\section{1}

Effects of oral cyclotropium bromide, scopolamine n-butyl-bromide, and placebo on gastric emptying and antral motor activity in healthy man

G Stacher, H BERgMANN, E HAVLIK, G SCHMIERER, AND S SCHNEIDER (Vienna, Austria) Cyclotropium bromide, a new antimuscarinic agent, inhibits gastrointestinal motility in animals at lower doses than gastric acid secretion and salivation. In man. cyclotropium bromide suppresses fasting and meal-stimulated colonic motility. This study investigated the effects of single oral doses of $60 \mathrm{mg}$ cyclotropium bromide, $60 \mathrm{mg}$ scopolamine n-butylbromide, and placebo on gastric emptying rate and on antral motor activity. Twentyfour healthy men (mean age 25 years) participated in three experiments one week apart. The drugs were administered, in random double-blind fashion. 30 minutes before the ingestion of a semi-solid test meal labelled with ${ }^{49 \mathrm{~m}} \mathrm{Tc}$ sulphur colloid. A gamma camera coupled to a computer monitored modulation depth. frequency. and propagation velocity of antral contractions together with gastric emptying.

The results show that cyclotropium bromide reduced modulation depth $(21.8 \pm 1.0 \%)$ compared with placebo $(26 \cdot 8 \pm 1 \cdot 1 \%)$ as did scopolamine n-butylbromide $(24.4 \pm 0.9 \%)$ to a lesser extent Gastric emptying measured as T50 was slightly delayed by scopolamine n-butyl- bromide $(64 \cdot 2 \pm 7 \cdot 1 \mathrm{~min})$ compared with placebo $(52.9 \pm 4 \cdot 3 \mathrm{~min})$, and much more so by cyclotropium bromide $(102.9 \pm 16 \cdot 3$ min). Neither drug affected frequency $(3.05 \pm 0.03 \mathrm{c} / \mathrm{min})$ or propagation velocity $(2 \cdot 6 \pm 0.2 \mathrm{~mm} / \mathrm{sec})$. Scopolamine $\mathrm{n}$-butylbromide effects on modulation depth $(F=4 \cdot 15, p<0 \cdot 05)$, but not on gastric emptying, differed significantly from placebo. Cyclotropium bromide was significantly more active on modulation depth $(F=13.86, p<0.001)$ and on gastric emptying $(F=14.01, p<0.001)$ than, on the average, scopolamine n-butyl-bromide and placebo. No adverse side effects occurred with any one treatment. In conclusion, cyclotropium bromide is a potent inhibitor of antral motility and gastric emptying.

\section{2}

Dopaminergic and $\beta$-adrenergic influence on gastric antral motility in dogs with gastric fistula

K BECH, C P HOVENDAL, AND D ANDERSEN (Odense, Denmark) Dopaminergic and $\beta$-adrenergic (isoprenalin) receptor stimulating drugs have been shown to inhibit gastric antral motility. The effect was significantly blocked by either the peripherally acting dopaminergic blocker domperidone or different $\beta$-adrenoceptor blockers. The purpose of the present study was to evaluate the effect of domperidone (dopaminergic), practolol ( $\beta_{1}$-receptors), H $35 / 25$ ( $\beta_{2}$-receptors), or propranolol $\left(\beta_{1}+\beta_{2}\right.$-receptors $)$ on pentagastrin- and bethanechol-stimulated antral motility. Gastric acid secretion was measured simultaneously.

Antral motility was measured in beagle dogs $(n=5)$ with gastric fistula by using intraluminal miniature strain-gauge transducers and expressed as mean amplitude (MA) and mean contractile index (MCI). Motor activity was changed into a digestive pattern by the continuous infusion of pentagastrin (median MA $=45.6(35.8$ $68 \cdot 9)$, median $\mathrm{MCI}=4 \cdot 1(3 \cdot 5-4 \cdot 8)$ ), while bethanechol induced a pattern similar to phase 3 in the interdigestive complex (median $\mathrm{MA}=194 \cdot 1 \quad(154 \cdot 8-384 \cdot 0)$. median $\mathrm{MCI}=10 \cdot 7(8 \cdot 0-19 \cdot 0)$. The steady state activities were not changed by any of the blocking drugs.

These results suggest that under physiological conditions there might be no adrenergic inhibition of gastric muscle activity. The blocking drugs had a modest effect on gastric acid secretion after 
vagotomy suggesting the sympathetic effect becomes apparent after vagotomy. We are looking to see whether this is also true for gastric motility.

23

Adaptive tracking of human slow-wave frequencies changes using surface and serosal signals

D A LINKENS, B LEVY, S J RIMMER, A JOHNSON, AND C J STODDARD (Sheffield, UK) Abdominal surface electrode recordings can detect human antral slow-waves noninvasively, but not electrical spike activity. Ten patients with implanted antral serosal electrodes have been studied to determine the transient tracking behaviour of slow waves at the surface. To detect rapid, smal changes in slow-wave characteristics, conventional spectral analysis is not suitable. Results are shown using two computer algorithms capable of tracking rapid fluctuations in frequency.

The first method is an off-line method and uses a modified form of auto-regressive modelling (ARM) analysis which displays frequency, amplitude, and harmonic content vs time. Frequency is displayed vertically, and the time axis is divided into two minute segments. Each 'box' indicates a significant frequency, with its height being directly related to amplitude, and its width inversely related to band width. Using the ARM method, tracking to within $5 \%$ has been found between antral and surface frequencies. During quiescent conditions, frequency changes of about $10 \%$ have been recorded in the antrum, and hence these can be observed at the surface. During antral contractions, larger frequency transients occur and these are accompanied at the surface by changes in harmonic content and amplitude. These amplitude changes agree with previous canine studies.

The second method uses an on-line least mean square (LMS) adaptive tracking algorithm. The data are logged at $1 \mathrm{~Hz}$ and tracked in real-time on a Texas 9900 based microcomputer system. The fluctuating frequency components are displayed on a graphics terminal with an update every minute. The LMS algorithm parameters can be 'tuned' to allow for either fast frequency fluctuations or large noise content as often happens in surface recordings. The method has also been applied to human serosal duodenal recordings, showing small frequency fluctuations of less than 5\% during quiescent periods.
Similar changes occur during phases 1 and 2 of migrating myoelectrical complexes with large fluctuations of up to $15 \%$ during phase 3 of a migrating myoelectrical complex.

It is concluded that off-line ARM analysis and on-line LMS adaptive tracking of human surface recordings give a visual display of several characteristics of gastric slow-waves which may enable contractions to be observed non-invasively. Very small frequency fluctuations can be tracked accurately in serosal recordings and appear to correlate with the occurrence of migrating myoelectrical complexes

\section{4}

Comparative effects of acute and chronic administration of ranitidine and cimetidine on gastric emptying of a mixed meal in man

R CORINALDESI, C SCARPIGNATO, ${ }^{*}$ A GALASSI, R CALAMElli, E ZARABINI, $\dagger$ G BERTACCINI, AND I. BARBARA (Bologna, Parma, Faenza, + Italy) The effect of acute intravenous and chronic oral administration of ranitidine, cimetidine, and placebo on the gastric emptying of a standard mixed meal was studied in a cross-over design. In 15 healthy volunteers the study was performed on three different days, one week apart, cimetidine $(300 \mathrm{mg})$, ranitidine (50 $\mathrm{mg}$ ), and placebo (saline) being administered five minutes before the meal. Ten duodenal ulcer patients were given ranitidine ( $150 \mathrm{mg}$ twice daily), cimetidine (40) $\mathrm{mg}$ twice daily), and placebo for two weeks, in a cross-over design. The last dose was administered four hours before gastric emptying time measurement. The meal (meat, corn oil, bread, milk pudding, and water) contained two different markers: ${ }^{5} \mathrm{CrCl}_{3}$, firmly incorporated into meat, for the solid phase and ${ }^{99 \mathrm{~m}} \mathrm{Tc}$ sulphur colloid, stirred up into water, for the liquid phase. The radioactivity on the gastric area was measured by a gamma-camera every 10 minutes, for 90 minutes. Gastric emptying was expressed as 'Emptying Index' at 90 minutes $(\mathrm{EI} 90 \mathrm{~min}=100-\mathrm{RR} 90 \mathrm{~min} / \mathrm{A} 90$ $\mathrm{min})$, where $\mathrm{RR}$ is the residual radioactivity (\%) and A $90 \mathrm{~min}$ is the area under the RR curve between 0 and 90 minutes.

In the healthy volunteers, intravenous ranitidine significantly $(p<0 \cdot 05)$ reduced the emptying index for both liquids $(0.40 \pm 0.03)$ and solids $(0 \cdot 38 \pm 0 \cdot 03)$ compared with placebo $(0 \cdot 49 \pm 0 \cdot 04$ and $0 \cdot 48 \pm 0 \cdot 05)$; intravenous cimetidine had no significant effect $(0.51 \pm 0.04$ and $(0 \cdot 49 \pm 0 \cdot 05)$ compared with placebo. In the duodenal ulcer patients there were no significant differences in the emptying indices for solids or liquids between any of the three treatments (oral placebo, oral cimetidine, oral ranitidine).

These results, in accordance with our previous data, suggest that only high blood levels of ranitidine, elicited by intravenous administration, are able to delay gastric emptying. Conversely, at steady-state levels elicited by conventional therapeutic doses, no effects on gastric emptying are evident.

\section{5}

Twenty-four hour gastric pH measurement in the diagnosis of duodeno-gastric reflux

N PANDOLFO, M BORTOLOTTI, * G BORGONOVO, AND F MATTIOLI (Genova and Bologna, ${ }^{*}$ Italy) The aim of the study was to test the value of the 24 intragastric $\mathrm{pH}$ measurement in the diagnosis of duodeno-gastric reflux.

Six asymptomatic young volunteers and 42 patients with histological evidence of antral gastritis, and without inflammatory lesions of the fundus, were studied. The examination was performed by positioning the exploring $\mathrm{pH}$ electrodes at about $9 \mathrm{~cm}$ from the radiological pylorus; the position of the probe was controlled radiographically during and at the end of the test. The reference $\mathrm{pH}$ electrodes was fixed to the patient's arm. The electrodes were connected with a portable battery $\mathrm{pH}$ instrument and with a recorder, both fixed to the patient's belt. The tracing obtained during 24 hours were evaluated by calculating the percentage of time intragastric $\mathrm{pH}$ was between 0 and 4.4 and 7 . higher than 7.

In all patients gastric acid secretion was also evaluated either in basal conditions and after maximal stimulation. No achlorhydric patients were admitted to our study.

The results show that the percentage of time when $\mathrm{pH}$ values were between four and seven was significantly (p ().(01) higher in patients with antral gastritis $(30.5 \pm 20.7 \%)$ than in controls $(3.9 \pm 1.7 \%)$; and that the percentage of time when $\mathrm{pH}$ values were above seven was significantly $(\mathrm{p} 0.05)$ higher in patients with antral gastritis $(8 \cdot 0 \pm(0 \cdot 7)$ than in controls $(0 \cdot 2 \pm 0 \cdot 4)$. In controls the $\mathrm{pH}$ was above only during a meal and never in fasting conditions; and in patients with antral gastritis, the highest $\mathrm{pH}$ values were recorded during sleep. 
26

Gastric evacuation in duodenal ulcer disease patients, as assessed by radiopaque pellets, differs according to the secretory status

J BERTRAND, E DANQUECHIN DORVAL, AND E H METMAN (Tours, France) It is generally accepted that gastric evacuation is accelerated in patients with duodenal ulcer disease when compared with healthy subjects. In this prospective study. evaluation time was estimated for these patients and compared with normal subjects after a mixed meal. The duodenal ulcer patients were then separated into two groups based on their respective secretory status.

Seventy-four subjects were involved in this study: 49 healthy controls and 25 patients having active duodenal ulcer disease confirmed by endoscopic examination, without stenosis and untreated. The 25 duodenal ulcer patients underwent an examination to determine the gastric acid secretion provoked by pentagastrin $(6 \mu \mathrm{g} /$ $\mathrm{kg} / \mathrm{h}$ ) with the determination of the PAO index (observed $\mathrm{PAO} /$ theoretical PAO $\times 10(0)$. Among them, 12 were normosecretors $(\overline{\mathrm{x}} \pm 2 \mathrm{SD}=100 \pm 50)$ and the remaining 13 hypersecretors (PAO index greater than 150). All 74 subjects then were studied for gastric secretion after a standard normal mixed meal lasting 30 minutes (836 Kcal, P 36 g. L 42 g. G 77 g). One hundred inert radiopaque polyethylene pellets were incorporated into the meal (pellet volume $30 \mathrm{~mm}^{3}$ ) and those pellets remaining in the gastric cavity were radiographically determined at fixed intervals after the beginning of the meal (90) 150,210, and $300 \mathrm{mn}$ ). This technique has been previously described and found to be valid.

The results suggest that the group composed of duodenal ulcer hypersecretors presented a PAO index significantly greater than duodenal ulcer normosecretors $(189 \cdot 6 \pm 44.9$ vs $102 \cdot 5 \pm 33 \cdot 4$ respectively: $p<() \cdot(001)$. It was further seen that duodenal ulcer hypersecretors have a gastric evacuation essentially similar to that seen in normal subjects. With respect to the control population, however, duodenal ulcer normosecretors have an accelerated gastric evacuation at $90 \mathrm{mn}(\mathrm{p}<0 \cdot 005), 150$ $\mathrm{mn}(\mathrm{p}<0 \cdot() 2)$, and $210 \mathrm{mn}(\mathrm{p}<0 \cdot 05)$, but there is no significant difference at $300 \mathrm{mn}$.

It is concluded that in a duodenal ulcer population, only duodenal ulcer normosecretors have an accelerated gastric evacuation after a mixed meal. This acceleration is seen especially at the beginning of the evacuation cycle and this mechanism might explain the increase in duodenal acid output in spite of the absence of acid hypersecretion.

\section{7}

Coordination of gastric and duodenal interdigestive motility effect of metoclopramide

P C L.EDERER, H LAUTERBACH, W SCHMITT, W DOMSCHKE, AND G LUX (Erlangen, FR Germany) The aim of the present study was to define the coordination of motility events within the antrum, the pylorus, and upper duodenum during fasting state and after stimulation with metoclopramide.

Using perfused catheters the pressure profile was obtained in seven healthy subjects (six men, one woman). Eight recording sites were located within the antrum, pylorus, and duodenum. Two sites within the pylorus and nearby duodenum were monitored by sleeve catheters which recorded pressure over a distance of 3 and $6 \mathrm{~cm}$ respectively. Two sites were located in the antrum $6 \mathrm{~cm}$ apart, four more in the duodenum starting in the bulbus each $2 \mathrm{~cm}$ apart. Recording lasted for two motor complexes and one hour after the administration of $10 \mathrm{mg}$ metoclopramide intravenously, which was given just after the second motor complex.

The pylorus and bulbus were involved in the cyclic pattern of interdigestive motility. During phase 3 the pylorus and bulbus showed the characteristics of a transitional segment with both gastric and duodenal motor pattern. Neither the pylorus nor bulbus displayed raised tonic pressure typical for a sphincter with relaxation in relation to gastric peristalsis. During both phases 2 and 3 highest pressure was recorded in the pylorus and bulbus: $95 \%$ of their contractions followed each other with a delay of one to two seconds. Activity in the duodenum can be described as follows: during phase $186 \%$ segmental contractions without proximal activity, $10 \%$ propulsive peristalsis restricted to the duodenum. only $4 \%$ peristalsis starting in the antrum. During phase 2 the distribution changed to $37 \%$ segmental contractions. $40 \%$ propulsive peristalsis descending from proximal. Retrograde peristalsis could be shown in $4 \%$ of contractile activity. Ten milligrams metoclopramide intravenously just after the end of the second motor complex elicited a motor pattern similar to that in phase 2. Antiperistalsis was seen in only two percent.
Manometrically the pylorus does not show the features characterising a digestive sphincter. The antroduodenal segment may be described as a transitional zone as far as motility is concerned. Metoclopramide shortens phase 1 and elicits the typical phase 2 motor pattern.

\section{8}

Gastric emptying and duodeno-gastric reflux in patients with gastro-oesophageal reflux

F MATTIOLI AND $N$ PANDOLFO (Genova, Italy) Recent studies reveal that some patients with reflux oesophagitis do not benefit from antireflux surgery. These unsatisfactory results could be related to the coexistence of motility disorders of the gastro-duodenal tract. The aim of this study was to establish the presence and the severity of the gastro-duodenal dyskinesia in patients with gastro-oesophageal reflux.

Thirty-six consecutive patients with symptoms of gastro-oesophageal reflux were admitted to the study. which was performed by means of 24 hour oesophageal and intragastric $\mathrm{pH}$ monitoring and by determining gastric emptying-time using the Madsen and Rasmussen method.

On the basis of our study, it was possible to distinguish two groups of patients: (1) group A: patients with acid gastrooesophageal reflux in whom intragastric $\mathrm{pH}$ was normal $(\% / \mathrm{c}$ time $\mathrm{pH}>7=0)$ and gastric emptying time $(220 \pm 81.3 \mathrm{~min})$ was not significantly different from normal values $(168 \pm 26 \cdot 8)$; (2) group $B$ : patients with alkaline or both acid and alkatine gastro-oesophageal reflux in whom intragastric pH was abnormal ( $\%$ t $\mathrm{pH}>7=8 \pm 6.8)$ and gastric emptying $(490 \cdot 1 \pm 90 \cdot 4)$ significantly $(p<0 \cdot 01)$ delayed.

Our results suggest the existence of two types of refluxers: the first (group A) in which motor dysfunction is only limited to lower oesophageal sphincter. the second (group B) in which the dysfunction also involves the gastro-duodenal tract. Therefore, antireflux surgery is probably adequate in patients of the first group, but is inadequate in patients of the second group because it cannot prevent duodenogastric reflux and normalise a delayed gastric emptying.

\section{9}

Chronic idiopathic intestinal pseudo- 
obstruction in infancy. A smooth muscle disease

T R FENTON, B D LAKE, L SPITZ, H H NIXON, J T HARRIES, AND P J MILLA (London, $U K$ ) Chronic idiopathic intestinal pseudoobstruction presents most commonly during the first year of life and carries a high mortality rate. Knowledge of the pathophysiology of the pseudo-obstruction is fragmentary.

We have studied small intestinal motility and muscle histology in five infants with chronic idiopathic intestinal pseudoobstruction using constantly perfused triple lumen catheters for manometric and myoelectric recordings and full thickness small intestinal biopsies for light and electron microscopy.

Small intestinal fasting motility was abnormal in all patients with no phase 1 or phase 2 activity. Migrating motor complexes were clearly identified in one patient and in three other patients migrating motor complex-like rhythmic activity was present which did not propagate. The amplitude of these contractions were reduced compared with control subjects (chronic idiopathic intestinal pseudo-obstruction mean pressure $27.5 \pm 8.5 \mathrm{~cm} \mathrm{H}_{2} \mathrm{O}$; controls $63+19.22 \mathrm{~cm} \mathrm{H}_{2} \mathrm{O}, \mathrm{p}<0 \cdot(02)$. Myoelectric activity showed an impaired rise in transmural potential difference associated with migrating motor complexes and migrating motor complex-like activity (chronic idiopathic intestinal pseudo-obstruction $3.8 \pm(0.80 \mathrm{mV}$; controls $9 \cdot 65 \pm 1.50 \mathrm{mV}$. $\mathrm{p}<0.001)$. The basic electrical rhythm varied from three to 14 cycles per minute in the patients compared with a mean of $11.6 \pm 1.3 \mathrm{cpm}$ in control subjects. Full thickness small intestinal biopsies showed marked abnormalities of the muscle coats.

These studies indicate that the pseudoobstruction is secondary to striking functional and morphological abnormalities of muscle and the data are consistent with a primary smooth muscle disease.

30

Anal sphincter function after pelvic ileal reservoir

M PESCATORI AND A G PARKS* decd (Rome, Italy; London, $U K^{*}$ ) Forty-two patients who underwent restorative proctocolectomy for ulcerative colitis and familial polyposis at St Mark's Hospital were followed up between one month and five years. At operation the diseased large bowel was removed and an ileal pouch was constructed and sutured to the anal canal. avoiding a permanent ileostomy.

Resting tone, voluntary contraction. rectoanal reflex, and pouch capacity were recorded by balloons; Student's $t$ test was used for statistical comparisons. The reflex was present in $54 \%$ of cases; the mean $( \pm \mathrm{SE})$ resting tone being $66( \pm 3)$, voluntary contraction $123( \pm 9) \mathrm{cm}$ water and PC $412( \pm 32) \mathrm{ml}$. All patients had full control of bowel motions: eight had slight leakage, mainly at night, related to a low resting tone of $50( \pm 2) \mathrm{cm}$ water. Further pre- and postoperative studies showed a significant $(<0 \cdot(001)$ reduction of resting tone from $89( \pm 7)$ to $62( \pm 7) \mathrm{cm}$ water with no decrease of voluntary contraction. Early and late postoperative recordings, when compared, showed a significant increase of resting tone $(\mathrm{p}<0 \cdot()(0) 1)$ from 52 $( \pm 5)$ to $68( \pm 7) \mathrm{cm}$ water and pouch capacity $(\mathrm{p}<0 \cdot 001)$ from $333( \pm 55)$ to 479 $( \pm 52) \mathrm{ml}$, thus explaining the resolution of temporary soiling.

It is, therefore, concluded that the internal sphincter is affected in the early postoperative months, but its function tends to normalise afterwards; and that an increase in pouch capacity has to be expected after surgery and should be considered when making the reservoir. Gross faecal incontinence is unlikely after restorative proctocolectomy as striated sphincter is not damaged; and leakage may be minimised by selecting patients with high preoperative resting tone.

\section{1}

Anorectal function after low anterior resection for cancer recti

H HEDLUND, S FASTH, AND L HULTÉN (Göteborg, Sweden) Urgency, soiling. and flatus incontinence are common problems after low anterior resection. The aim of the present study was to elucidate to what extent the different physiological mechanisms subserving continence are affected by this operation.

Six patients, aged 47-70 years, treated for rectal carcinoma with low anterior resection were studied. Anorectal function was evaluated postoperatively. six to eight weeks and three to six months postoperatively by simultaneous recording of rectal volume, rectal motility, and anal pressure during isotonic rectal distension ( $40 \mathrm{~cm} \mathrm{H}_{2} \mathrm{O}$ ).

The results show that preoperative anal pressure amounting to $76 \mathrm{~mm} \mathrm{Hg}$ (range 70-87) was not significantly changed at the postoperative recordings. Normal anorectal inhibition was also found in all patients both pre- and postoperatively. In contrast the rectal volume was greatly reduced at the first postoperative control, the mean volume amounting to $60 \mathrm{ml}$ (30-85) as compared with $120 \mathrm{ml}(75-175)$ preoperatively. At the second postoperative control rectal volume was partly restored $(90 \mathrm{ml}: 7(-120)$. Postoperatively the rectal adaptation to distension was abolished. Instead repeated strong contractions were observed. The contractions were blocked by intravenous atropine $(0 \cdot() 15 \mathrm{mg} / \mathrm{kg})$.

It is concluded that functional disturbances after low anterior resection does not seem to be because of sphincter dysfunction. A deficient volume adaptation instead might explain the symptoms. The inhibition of the pathological contractions after atropine indicates that the symptoms might be relieved with anticholinergic agents.

\section{2 \\ Effects of oleic acid on gastric emptying and gastroduodenal motility}

O KEINKE: AND) H-J EHRLEIN (Stuttgart, FR Germany) The aim of this study is to show in which way the regulating factors of gastric emptying are altered by oleic acid. In four conscious dogs the gastroduodenal motility was measured with strain gauge transducers and induction coils during emptying of two test meals (mashed potatoes. mashed potatoes and oleic acid). Radiography was used to measure gastric emptying and to observe the transport of the ingesta. There were several reasons for this: (1) a specific pattern of contractions with phases of stronger and weaker activity was induced. In the duodenum groups of aboral migrating segmentations occurred, in the antrum the force and the depth of the contractions changed periodically. (2) The pylorus opened less and the resistance to flow was raised. Associated with the diminished antral contractions retropulsion of the ingesta increased. (3) The relation between the gastric body and the stomach was significantly greater, indicating less propulsion of contents from the gastric reservoir to the antral pump.

It is concluded that oleic acid induced a specific motor pattern, diminished the pyloric diameter and the intragastric propulsion. As a result of these co- 
operating factors gastric emptying was reduced.

33

Site of chemoselective resistance to gastric emptying of liquids

N S WILLIAMS, J MIII.FR. AND J MFYER (LOS Angeles, USA, and Leeds. UK) Glucose or oleate empty more slowly from the stomach than $0.15 \mathrm{M} \mathrm{NaCl}$. This chemoregulation may be achieved by resistance beyond the proximal stomach. We sought to define the site of this resistance by two experiments. (1) Gastric emptying of $0 \cdot 15 \mathrm{M} \mathrm{NaCl}$ and $600 \mathrm{mM}$ glucose was measured in five dogs with intestinal cannulas $45 \mathrm{~cm}$ distal to the pylorus while gastric pressure was maintained at 10,18 , or $26 \mathrm{~cm} \mathrm{H}_{2} \mathrm{O}$ with a barostat. The dogs were studied either with an uninterrupted intestinal stream or with duodenal effluent diverted through a second barostat before its return downstream. As the latter ensured a constant pressure at the ligament of Treitz, any observed effects on emptying could not be because of resistance further distally. (2) Emptying of $0.15 \mathrm{M} \mathrm{NaCl}$, glucose, and $40 \mathrm{mM}$ oleate emulsion was measured in five dogs without cannulas after control antroduodenal transection and after antrectomy while gastric pressure was controlled at 11,17 , and $23 \mathrm{~cm} \mathrm{H}_{2} \mathrm{O}$.

The results showed that emptying rates were expressed as the average (mean \pm SEM) of the volume emptied at the three pressures. Under both conditions in experiment 1 , emptying increased with pressure, yet $0 \cdot 15 \mathrm{M} \mathrm{NaCl}$ emptied faster than glucose (uninterrupted: $14 \cdot 8 \pm 2 \cdot 6 \mathrm{vs}$ $5 \cdot 6 \pm 2 \cdot 0, \mathrm{p}<0 \cdot 05$; diverted: $15 \cdot 3 \pm 4 \cdot 3 v \mathrm{vs}$ $3 \cdot 2 \pm 1 \cdot 4, \mathrm{p}<0 \cdot 05)$. Thus a major site of chemoselective resistance to emptying of liquids lies proximal to the ligament of Treitz. After antrectomy, $0 \cdot 15 \mathrm{M} \mathrm{NaCl}$ and oleate emptied faster $(\mathrm{p}<0.05)$ than before $(0 \cdot 15 \mathrm{M} \mathrm{NaCl}: 22 \cdot 2 \pm 3 \cdot 7$ vs $8 \cdot 6 \pm 2 \cdot 1$; oleate: $9 \cdot 3 \pm 1 \cdot 0$ vs $4 \cdot 1 \pm 0 \cdot 7)$. The differences, however, between saline and nutrients were maintained. Resistance, therefore, does not reside in the antrum or pylorus and clearly the duodenum is implicated.

\section{4 \\ Effect of alcohol on gastric emptying of an ordinary meal in man}

R JIAN, F DUCROT, Y NAJEAN, A CORTOT, AND $\mathrm{R}$ MODIGLIANI (Paris, France) The reported effects of alcohol on gastric emptying of a solid-liquid meal are rare and conflicting. An isotopic method was used, therefore, to assess the influence of alcohol on emptying of a solid-liquid meal.

Six healthy volunteers ate a meal $(500$ cal, $500 \mathrm{ml}$ ) in which ${ }^{99 \mathrm{~m}}$ Technetium sulphur colloid-tagged egg was the solid marker and ${ }^{111}$ Indium chloride the liquid phase marker. The specificity of labelling was previously determined. Each subject received, on separate days, the meal with alcohol $(1 \mathrm{~g} / \mathrm{kg})$ or an equivalent volume of water. No attempt was made to maintain isocaloricity between the two study days in order to assess the effects of alcohol in the usual condtions of drinking. Gastric emptying was assessed by differential gamma camera monitoring with double antero-posterior detection every 20 minutes for three hours; plasma samples were taken every 30 minutes.

Plasma ethanol levels reached $68+24 \mathrm{mg}$ $\%(\mathrm{M} \pm \mathrm{SD})$ at 20 minutes and remained stable thereafter. Emptying of the solid marker (expressed as percentage ingested activity emptied/h; $\mathrm{M} \pm \mathrm{SD}$ ) was markedly delayed by alcohol (22 \pm 6 vs $32 \pm 4$; $\mathrm{p}<0.01)$; this effect persisted for three hours. Emptying of the liquid marker was also significantly $(\mathrm{p}<0 \cdot 01)$ delayed but this effect was smaller $(p<0.01)$ than that obtained with solids and could be linked to the fraction of liquid marker adsorbed on solids.

Thus, alcohol taken with a meal markedly delays gastric emptying of solids and slightly that of liquids.

35

Disorganisation of the small bowel transport pattern by systemic administration of heat-stabile enterotoxin in rats

E STAHLE, S GUSTAVSSON, B RÖNNBERG, T WADSTRÖM, AND T WILÉN (Uppsala, Sweden) In the interdigestive state the migrating myoelectric complexes result in the formation and transport of small bowel luminal contents in distinct portions. Hypothetically, one purpose of this arrangement of motility is the protection against intestinal colonisation of invasive bacteria. In this paper we report the effect of a diarrhoeagenic $E$ coli toxin on the formation of small bowel luminal portions, and the possible mediating effect of prostaglandins for this type of diarrhoea.

The small bowel transport pattern was studied in fasting rats by intravenous infusion of a bile-excreted radiopharmaceutical $\left({ }^{99} \mathrm{Tc}^{\mathrm{m}}\right.$-Solco-HIDA) and subse- quent determination of the activity $\stackrel{\overrightarrow{\vec{\omega}}}{\vec{\sigma}}$ distribution along the excised bowel 음 specimen. Heat-stable enterotoxin was produced by human enterotoxigenic $E$ coli $\frac{\bar{S}}{\partial}$ strains not producing heat-labile, cholera- $\mathbb{D}$ like toxin. Heat-stable enterotoxin was a administered perorally, intravenously, and $s$ intraperitoneally. One group of animals $\overrightarrow{0}$ was pretreated by the prostaglandin $\vec{A}$ synthesis inhibitor indomethacin $\vec{\omega}$ (Confortid) $10-20 \mathrm{mg} / \mathrm{kg} / \mathrm{bw}$ intravenously.

Intravenous and intraperitoneal (but not peroral) administration of heat-stable $N$ enterotoxin resulted in a complete elimination of the normal, interdigestive appearance of the small bowel transport pattern with contents in separate portions. Instead, a continuous activity distribution was seen. 을 Heat-stable enterotoxin was active also after dilution 10 and 20 times. In animals $\square$ pretreated with indomethacin heat-stable enterotoxin did not change the normal interdigestive motility pattern.

The present findings suggest that a $\omega$ disturbance in the formation of small bowel luminal portions occurs early in the intestinal response to heat-stable enterotoxin. This disturbance is preventable by prostaglandin synthesis inhibitors. It is tempting to speculate that elimination of $\varnothing$ the efficient mechanism for clearing the $\overrightarrow{\overline{\hat{O}}}$ small bowel in the interdigestive state facilitates colonisation of the small bowel mucosa by invasive bacteria.

36

Effect of morphine on small bowel transit and electric spiking activity in conscious rats

M R E HUTTON, P DEAN, AND D L WINGATE 을 (London, $U K$ ) To study the relationship $D$ between patterns of electromyographic spike activity and the transit of intra- $N$ luminal content, adult rats were prepared $\mathscr{\Omega}$ either with chronically implanted jejunal $N$ and ileal serosal electrodes or with indwelling duodenal cannulae. In one $\omega$ group, electromyographs were recorded in conscious animals during fasting and after $a$ normal meal of rat chow. In the other $\mathbb{\Phi}$ group, bolus doses of ${ }^{51} \mathrm{Cr}$ (sodium? chromate) were delivered into the duodenum during fasting or after ad lib 우 feeding; 30 minutes later, the animals were $\mathbb{D}$ killed, and the distribution of isotope along $\mathbb{\mathbb { D }}$ the gut determined by passing a scanner at a constant speed along the length of the excised bowel. These studies were o repeated after the administration of morphine $(1 \mathrm{mg} / \mathrm{kg})$ subcutaneously.

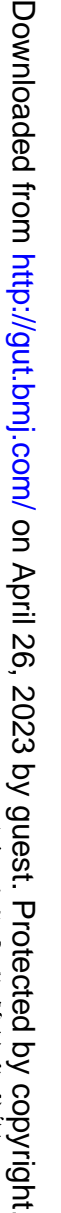


The electromyograph of the fasting gut was characterised by brief periods of regular spiking activity, at intervals of $14.06 \pm 0.64$ minutes, after quiescence, and preceded by irregular spiking activity. Food invariably replaced periodic regular spiking activity with continuous irregular spiking activity. Isotope transit during fasting was uneven, with aggregation into one or more peaks; surprisingly, after food, the distribution of isotope along the bowel was similar, although the transit velocity of the leading edge was decreased, and significantly $(p<0 \cdot(0) 1)$ fewer peaks were seen after food. The effect of morphine on the fasting electromyograph was the abolition of irregular spiking activity in between the periods of regular spiking activity; in fed rats, morphine abolished postprandial irregular spiking activity replacing it with periodic regular spiking activity similar to that seen in fasting. The effect of morphine on isotope transit was a reduction in transit velocity in both fasted and fed rats.

Our studies show that in the rat, postprandial transit of luminal content is slower than during fasting; the effect of morphine is the slowing of transit in both fasted and fed rats and also a marked reduction in irregular spiking activity in both states. These data suggest that, in this species, it is irregular spiking activity (and not periodic regular spiking activity) which is important in the transit of nutrient. The effect of morphine on spiking activity is similar to that reported with the administration of opiates to dog and man. Finally, it is clear that the distribution and velocity of transit of intraluminal content cannot easily be inferred from patterns of spike activity.

\section{7}

VIP immunoreactive (VIP-IR) nerves in achalasia

G GRIDELLI, R BUFFa, * P SALVINI, P DE RAI, $\mathrm{F}$ UGgeri, E SOlCIA ${ }^{*}$ (Milano, Pavia, ${ }^{*}$ Italy) In the oesophageal wall a nonadrenergic, noncholinergic inhibitory neuron is present that seems to have a critical role in the organisation of the oesophageal peristalsis. Recent studies suggest that VIP could be the transmitter released from enteric inhibitory nerves and that it relaxes both sphincter and non-sphincter parts of the oesophagus by direct action. On these bases we studied the distributive pattern of VIP-IR nerves in the surgical specimens of seven achalasic and seven normal subjects. In normal oesophagus at the oesophago- gastric junction a large number of VIP-IR varicose or non-varicose nerve fibres were detected. Groups of varicosities formed rings around non-reactive nerve cell bodies of the myenteric and submucosal plexus. Numerous nerve fibres were detected in smooth circular muscle. A few nerve cell bodies of the myenteric plexus reacted strongly to the anti-VIP antisera. No VIPIR nerves or terminals were found in the specimens from achalasic patients. It seems interesting that in achalasia, in which lower oesophageal sphincter relaxation and oesophageal peristalsis are impaired, VIP. IR nerves are lacking. In fact, achalasic patients have impairment of inhibitory nerves, as suggested by cholecystokinin-octapeptide infusion. Thus, the hypothesis that the absence of VIP-IR nerves represent the basic pathological lesion in achalasia seems attractive.

\section{8}

Myogenic control of antroduodenal coordination; cholinergic and dopaminergic modulation

J A J SCHUURKES AND J M VAN NUETEN (Beerse, Belgium) This study aims to determine the pathway by which antroduodenal co-ordination is controlled. either by the smooth muscle itself or by the myenteric plexus. Gastric peristalsis of an intact gastroduodenal preparation of the guinea pig was measured via a duodenal cannula detecting changes in gastric volume. The occurrence of duodenal contractions was marked concomitantly. Both tetrodotoxin (TTX, $5 \times 10^{-7} \mathrm{M}$ ), as well as atropine $\left(2.9 \times 10^{-7} \mathrm{M}\right)$ blocked antroduodenal co-ordination suggesting that the cholinergic nervous tone is a prerequisite for the occurrence of antroduodenal co-ordination. In the presence of TTX, the cholingergic agonist bethanechol $\left(E D_{50} \sim 3.8 \times 10^{-7} \mathrm{M}\right)$ improved co-ordination to maximum $75 \%$, indicating that antroduodenal co-ordination is mediated via a myogenic pathway.

Dopamine impaired co-ordination in a dose-related manner. The inhibition of this effect by the dopamine antagonist domperidone showed competitive characteristics. Domperidone $\left(E_{50}\right.$ $\left.\sim 1.4 \times 10^{-7} \mathrm{M}\right)$ itself stimulated antroduodenal co-ordination to maximum $90 \%$ via specific dopaminergic receptor sites. This effect was blocked by pretreatment with TTX (in vitro) or with 6hydroxydopamine (in vivo).

It is concluded that antroduodenal co- ordination is intrinsically controlled by the smooth muscle itself. Co-ordination is subjected to modulation by inhibitory, possibly dopaminergic nerves. The only function of the cholinergic tone might be to provide the stimulus for contractions thereby revealing the co-ordinated antroduodenal motor patterns.

\section{9}

Intramural neural mechanisms involved in the antiperistaltic and the segmentation movements of the large intestine

M BOUVIER AND Y JULE (Marseille, France) In the present investigation the intramural neural mechanisms involved in the ascending excitation of the proximal colon of the rabbit in response to intraluminal distension have been studied in vivo using an electromyographic technique.

Distension of the colon by inflating a balloon into its lumen gave rise to one or two antiperistaltic waves generated at the level of the balloon and propagated up to $20 \mathrm{~cm}$. For prolonged distension (over five seconds) antiperistaltis ceased and was followed by segmentation elicited exclusively at the point of distension. Hexamethonium abolished both types of excitation. Atropine blocked peristalsis but did not affect the segmentation. The action of these drugs shows that antiperistalsis was cholinergically mediated whereas the segmentation involved at least two types of synapses: a cholinergic one (through nicotinic receptors), and a non-cholinergic one.

The effects of distension on the excitatory junction potentials and the inhibitory junction potentials obtained in response to vagal stimulation indicate that. at the level of the balloon, the excitatory cholinergic intramural pathway was facilitated, whereas the inhibitory nonadrenergic non-cholinergic pathway was blocked. Above the balloon opposite effects were observed. These data show that antiperistalsis and segmentation result from a simultaneous and co-ordinated activation of the excitatory cholinergic and the inhibitory non-adrenergic noncholinergic pathways along the colonic wall.

\section{0}

Modifications induced by atropine on colonic myoelectrical activity in man

G ROZENTAL, J FREXINOS, J J TASSOU, P M 
MOUNIELOU, AND J FIORAMONTI (Toulouse, France) The purpose of the present investigation was to define the basic modifications of the two myoelectrical activity components after atropine injection.

The electrical activity probe exhibits two kinds of spike activity: short spike bursts and long spike bursts.

Colonic myoelectrical activity was recorded from 10 fasting subjects with irritable colon syndrome, during six hours. Two hours after the beginning of the recording. $15 \mu \mathrm{g} / \mathrm{kg}$ atropine sulphate was injected subcutaneously in seven subjects and $4 \mathrm{ml} \mathrm{NaCl} 9 \%$ to the three others. A quantitative evaluation of total electrical activity (long spike bursts + short spike bursts) and propagated electrical activity (long spike bursts) was performed one hour before and two hours after the injection.

The results show that atropine induces a dramatic decrease in the total electrical activity beginning after $30 \mathrm{mn}$ and lasting two hours. This decrease concerns short spike bursts activity but not propagated long spike bursts whose decrease is not significant.

Our hypothesis concludes that in man. the inhibition of colonic motility by an anticholinergic does not affect equally the two components of the electromyogram. It may be supposed that the absence of significant decrease of long spike bursts activity means that this type of propulsive activity is not, in basal conditions, under exclusive cholinergic control.

41

Abnormalities of postprandial small intestinal motor activity in childhood: their role in the pathogenesis of irritable bowel syndrome

T R FENTON, J T HARRIES. AND $P$ J MILLA (London, UK) Toddler diarrhoea, or the irritable bowel syndrome in childhood, is the commonest cause of chronic diarrhoea without failure to thrive in childhood, yet little is known of the pathophysiological mechanisms.

Using constantly perfused triple lumen catheters we have previously shown that the fasting small intestinal motor activity is normal in these children, but in contrast with controls their migrating motor complexes are not disrupted by intraduodenal dextrose.

With the same technique we have shown that postprandial activity is induced by constant duodenal perfusion of milk formulae and isosmotic hexose solutions in children with a variety of disorders. When compared with those subjects $(n=9)$ whose migrating motor complexes were disrupted by intraduodenal dextrose (group 1). subjects $(n=10)$ whose migrating motor complexes were not disrupted by intraduodenal dextrose (group 2) showed differences in their postprandial activity.

Normal postprandial activity was induced in only six out of 10 in groups $2 \mathrm{vs}$ nine out of nine in group 1 . The return of fasting activity (signalled by the appearance of a migrating motor complex) was faster in group 2, occurring in less than 30 minutes in five out of six subjects $v s$ one out of five in group 1. Migrating motor complexes were seen during the duodenal perfusion in four out of 10 of group $2 \mathrm{vs}$ none out of nine in group 1.

We suggest that these abnormalities in postprandial activity play a role in the pathogenesis of the diarrhoea in children with irritable bowel syndrome.

\section{2}

Slow wave and spike activity in the feline gut after prolonged fasting

M M KÖRNER, I ALTAPARMAKOV. AND M WIENBECK (Düsseldorf. FR Germany) The cat lacks typical migrating motor complexes for unknown reasons. We set out to look for other motor mechanisms in the feline small and large intestine after prolonged fasting.

Twelve cats were implanted with seven bipolar needle electrodes along the gut. Studies began two weeks after the implantation. Myoelectric activity was recorded intermittently in the unaesthetised cat after a 17 to 24 hour fast.

In the small intestine. intensive spike bursts occurred at irregular intervals from 10 to 30 minutes. Spike burst duration was 15.41. 15.98, and 2.43 seconds for duodenum. jejunum, and ileum respectively. They were accompanied by a disruption of slow wave activity which was followed by disturbances of slow wave amplitude and frequency. The drop in slow wave frequency after spike bursts was five in the duodenum. four in the jejunum. and two in the ileum.

The reduced slow wave frequency caused an intermittent inversion of apparent slow wave spread. In the large intestine slow wave frequency was not

altered. Periods of spike activity occurred at intervals of $24 \cdot 3 \pm 6 \cdot 6$ minutes.

In the fasted cat intermittently occurring spike bursts cause a profound disturbance of the myoelectrical activity of the small intestine. The new motor pattern indicates a retardation rather than an acceleration of propulsive motility which is different from fasted patterns in other species.

43

Small intestinal absorption and myoelectrical activity: the effects of laxatives and antidiarrhoeal agents

A J SHIRley, J COLLIN, AND I D A JOHNSTON (Newcastle upon Tyne and Oxford, UK) The effects of ricinoleic acid, loperamide and indomethacin on absorption and myoelectrical activity of the small bowel have been studied in dogs.

After isolating a $75 \mathrm{~cm}$ segment of small bowel, the ends were exteriorised and recording electrodes attached. The segment was perfused with an isotonic solution at a rate of $3 \mathrm{ml} / \mathrm{min}$ for consecutive one hour periods. The effluent was collected for analysis and the myoelectrical activity recorded.

After a 60 minute control period ricinoleic acid, loperamide, and indomethacin, alone or in combination, were added to the perfusate. Ricinoleic acid and loperamide increased the volume of effluent $(p<0.001$ and $p=0 \cdot 014)$ respectively. Fast wave activity, however, was decreased with ricinoleic acid $(\mathrm{p}<0.05)$ but increased with loperamide $(<0 \cdot 0001)$. Although indomethacin increased fast wave activity it did not alter the volume of effluent.

Compared with ricinoleic acid alone, the addition of indomethacin or loperamide significantly increased fast wave activity $(p=0.0001$ and $p=0.02)$ respectively, but only indomethacin significantly reduced the volume of effluent $(p=0 \cdot 02)$. The addition of ricinoleic acid to the perfusate containing indomethacin, however, significantly increased the volume of effluent $(p=0 \cdot 0001)$ without changing fast wave activity.

We conclude that indomethacin inhibits in part the effects of ricinoleic acid. This may be because of inhibition of prostaglandin synthesis and suggests that while prostaglandins inhibit fast wave activity this action appears to be independent of their effects on intestinal absorption. 
44

Motility patterns of the canine jejunum

M SChEMANN AND h J EhrLein (Stuttgart, FR Germany) The aim of the present study was to investigate whether characteristic patterns of jejunal motility are produced by different test meals.

A cellulose meal and an oleic acid cellulose meal were used. The jejunal motility was measured by multiple closely spaced strain gauge transducers in conscious dogs. Recordings were analysed by a computer in particular to evaluate the spread of contractions and the timedifferences between two adjacent recording sites. Our results show the cellulose meal induced a motility pattern which was characterised by regular strong contractions occurring at the maximal frequency. Analysis revealed a high motility index with short contractile intervals. Eight-five per cent of the recorded contractions were propulsive, and only $15 \%$ were segmental. Strong coordination between the contractions of adjacent recording site was indicated by a small variation of time-difference. Fluoroscopically, powerful propulsion of the jejunal ingesta was observed. In contrast, the oleic acid cellulose meal was associated with irregular weak contractions producing bursts and periods of inhibition. The motility index was low and the contractile intervals were prolonged. A large variation of time-difference indicated bad coordination. Forty-one per cent of the recorded contractions were segmental and $59 \%$ propulsive. Fluoroscopy confirmed the predominance of segmental activity and a slow transfer of ingesta. It is concluded that cellulose is a valuable test meal for motility studies of the gastrointestinal tract. It produces a characteristic motility pattern of the small intestine associated with a rapid transfer of ingesta. Oleic acid alters the patterns of motor activity definitely in various aspects.

45

Motor stimulatory effect of dopamine on human duodenum in vivo

L MARZIO, ${ }^{*}$ G A LANFRANCHI, ${ }^{\dagger}$ G BAZZOCCHI, $\dagger$ M NERI, ${ }^{*}$ C SCHIAVONE, ${ }^{*}$ AND F CuCCurullo* (Chieti, ${ }^{*}$ Bologna, $\dagger$ Italy) It has recently been shown that dopamine may have an excitatory effect on opossum duodenal smooth muscle in vitro. The purpose of this study was to analyse the action of dopamine on human duodenal muscle in vivo. Five healthy volunteers were studied. An oral-duodenal tube with three open tips was positioned in the proximal and middle duodenum under fluoroscopic control. Open tips were constantly perfused at a rate of $1.59 \mathrm{ml} / \mathrm{min}$ and recordings were made by means of a Dinograph R.612 Beckman ink recorder. Electrical activity was also recorded through a bipolar suction electrode placed on the tip of the oral-duodenal probe. After a 20 minute basal recording obtained during phase 2 of the interdigestive complex, dopamine was infused at $5 \mu \mathrm{g} / \mathrm{kg}$ min for 10 minutes, followed by 40 minutes of control. When the phase 2 pattern of interdigestive motility reappeared, a second 10 minute dopamine infusion was then repeated preceded by a pretreatment with domperidone $10 \mathrm{mg}$ intravenously as bolus. The results were analysed through the calculation of the motility index (mean amplitude $\times$ percentage of total duration of the waves) every 10 minutes. The results have shown that dopamine has a stimulatory motor effect that lasts from eight to 12 minutes after an inhibitory action that lasts for 10 to 20 minutes. The motor activity, at duodenal maximal intrinsic frequency, seems to be propagated so that it resembles phase 3 of the interdigestive complex. A specific role for dopamine in the occurrence of phase 3 of the interdigestive migrating complex is, therefore. proposed.

\section{6}

Nervous control of the gastrointestinal tract during vomiting

J P MIOLAN, A M LAJARD, P REGA, AND C ROMAN (Marseille, France) In conscious dogs with electromyographic electrodes implanted in the stomach and duodenal wall, vomiting is marked by inhibitory phenomena (suppression of spiking activity and reduction or abolition of the slow waves) after excitation phenomena observed only at duodenal level (prolonged burst of spikes propagated in the oral direction). All these phenomena are present under atropine, but suppressed by hexamethonium or bivagotomy. The duodenal antiperistaltic contraction might result not only from a post-inhibitory rebound, but also from a non-cholinergic excitatory mechanism. In order to elucidate this point, the effect of various drugs were tested - for example, inhibitors of prostaglandin or 5-HT synthesis and blockers of opiate receptors. Only benser- azide (an inhibitor of 5-hydroxytryptophan decarboxylase, that prevents 5-HT synthesis) produced a significant reduction of the vomiting-induced duodenal spiking activity. In contrast, chlorimipramine (an inhibitor of 5-HT re-uptake) resulted in a marked reinforcement of this activity. These results suggest that a serotoninergic mechanism is probably involved in the duodenal contraction occurring during vomiting.

\section{7}

Gall-stone dyspepsia, gall-bladder function, and duodenogastric reflux studies with the HIDA scan

I A EYRE-BROOK, A M HOLROYD, AND A ( JOHNSON (Sheffield, UK) We have previously reported preliminary results of non-invasive studies of duodenogastric reflux in gall-stone patients. We have now established the reproducibility of this technique and have investigated the association between gall-stone dyspepsia, gall-bladder function and reflux, before and one month after cholecystectomy.

Duodenogastric reflux was monitored scintigraphically; the position of the stomach being first established with intravenous "sodium pertechnicate $(100 \mu \mathrm{Ci}$ ). Biliary secretion after a Lundh meal was then studied dynamically (one minute frames) using technetium p-butyl immodiacetic acid (HIDA, $3 \mathrm{mCi}$ ). Reflux was recorded as the percentage of bile secreted by the liver which appeared in the stomach area.

Severity and frequency of each of nine symptoms of flatulent dyspepsia were scored separately on a three-point scale $(0-1-2)$; the scores being summated to provide a numerical value for flatulent dyspepsia (range ()-36). Scans were repeated in five patients without gall stones after one treatment-free month. Results were reproducible (mean discrepancy $1 \cdot 2 \%$ : range $-0 \cdot 4$ to $+3 \cdot(\%)$.

In 29 preoperative gall-stone patients. there was significant correlation between symptoms and reflux (Spearman Rank correlation coefficient $=(0 \cdot 6, \quad p<0 \cdot(0) 1)$. 'Significant' reflux $(>5 \%)$ was present in two of 13 patients with low symptom scores $(<5)$, in five of nine with intermediate $(5-10)$, and six of seven with high scores $(>10)$. Gall-bladder function assessed with the oral cholecystogram was not correlated with symptoms nor reflux. Postoperatively this correlation between symptoms and reflux was absent $(r=0 \cdot 25, p>0 \cdot(15)$. 
48

Evidence for a central control of intestinal motility by somatostatin and CCKoctapeptide in rats

L BUENO AND J FIORAMONTI (Toulouse, France) The effects of intracerebroventricular $v s$ intravenous infusion of somatostatin (GH-RIH) and CCKoctapeptide (CCK-8) on intestinal myoelectrical activity were investigated in 12 hour fasted rats presenting the typical migrating myoelectric complexes of the small intestine. In fasted rats, these migrating myoelectric complexes last 12-15 minutes and occur on the duodenum at about 20 minute intervals.

When injected continuously into the lateral ventricles of rat, GH-RIH increased the frequency of the migrating myoelectric complexes of the small intestine in a dose-related manner. At $0.20 \mathrm{pmol} / \mathrm{min}$ this increase was maximal $(p \leqslant 0 \cdot() 1)$ from 60 to 90 minutes after the beginning of infusion, the frequency of migrating myoelectric complexes reaching $6 \cdot 2 \pm 0 \cdot 9$ per hour vs $4 \cdot 4 \pm 0 \cdot 3$ for control infusion. A significant increase was obtained at a dose as little as $0.066 \mathrm{pmol} / \mathrm{min}$, a similar response being obtained for 200 times higher dose when injected intravenously.

In contrast, $\mathrm{CCK}_{x}$ immediately decreased the frequency of the migrating myoelectric complexes or disrupted this pattern when injected into the lateral ventricle at rates of $0.073-0.73 \mathrm{pmol} / \mathrm{min}$. At a rate of $0.23 \mathrm{pmol} / \mathrm{min}$, the frequency of migrating myoelectric complexes was nearly halved.

These findings support the hypothesis that somatostatin and CCK-octapeptide act on central nervous system structures that are involved in the control of intestinal motility.

49

Cholecystokinin-octapeptide and its role in the 'brain gut' axis

W R EWART AND D L WINGATE (London, $U K)$ Cholecystokinin-octapeptide appears to have a dual role in the gastrointestinal tract; a peripheral action on intestinal smooth muscle and, more recently, a central role in the suppression of feeding has been suggested. A model has been developed for the direct study of gut-brain interaction. Recordings were made using multibarrel micropipettes from single neurones in the dorsal vagal nucleus of anaesthetised rats, before, during, and after periods (10-30 seconds) of gastric distension using a water-filled balloon inserted through a gastrostomy. CCK-OP $(0.2 \mathrm{mM}, \mathrm{pH} 7.5)$ was applied iontophoretically and its effects on neuronal excitability and gastric distension responses observed. Twenty-three units were studied; the majority $(78 \%)$ of these neurones were excited by CCK-OP. In 14 units, the effect of CCK-OP on characteristic distension responses, previously described, was studied. CCK-OP modulated these responses in two principal ways; first, by augmenting the 'on' response and, secondly, by diminishing the depth of inhibition in neuronal activity observed during the 'off' response. On one occasion, 'transient' inhibition on inflation of the balloon was seen to be abolished by CCK-OP.

The experiments show not only the powerful effect of CCK-OP on neuronal excitability in the dorsal vagal nucleus but also that the central representation of gastric mechanoreceptor activity is susceptible to modulation by this brain-gut peptide.

50

The study of the prejunctional $\alpha$ adrenoceptor involved in the inhibitory effect of dopamine on the rat gastric fundus

R A LEFEBVRE, J P BLANCQUAERT, J L WILLEMS, AND M G BOGAERT (Gent, Belgium) As previous experiments suggested that the inhibitory effects of dopamine on the transmurally stimulated rat gastric fundus are mainly mediated by prejunctional $\alpha$-receptors and postjunctional $\beta$-receptors, further studies were carried out on rat fundus strips contracted by transmural stimulation or by mecholyl.

Experiments with cocaine and with preparations from reserpine pretreated animals suggest that the inhibitory effect of dopamine is largely indirect and because of the liberation of endogenous noradrenaline. When studying the direct effects of dopamine in the presence of cocaine, it is found that the dopamine antagonists domperidone. metoclopramide, and sulpiride partly inhibit the dopamine-effect, but that the noradrenaline inhibitory effect is antagonised to the same degree by these agents.

Finally, the experiments with noradrenaline, clonidine, phenylephrine and dopamine, and with prazosin and rauwolscine suggest that the prejunctional $\alpha$-receptors on the cholinergic nerve endings in the rat fundus have characteristics of both $\alpha_{1}$ and $\alpha_{2}$-adrenoceptors.

51

Temporal relationship between the spike bursts and the slow wave during the fasted and fed states

C MENDEL, A POUSSE, AND J F GRENIER (Strasbourg, France) The temporal relationship between the spike bursts and slow waves was investigated in the proximal jejunum, in three unrestrained dogs during the phases 2 and 3 of the migrating myoelectric complex, and after $\frac{D}{\omega}$ the dogs had received a standard canned of meal. More than 250000 slow wave cycles $ᄋ$ were processed using a fully automatic method. Computer programmes measured: the duration of each slow wave cycle on which a spike burst was superimposed, the time elapsed from the $\overrightarrow{\mathscr{C}}$ beginning of the cycle to the spike burst onset (spike burst onset delay) and the spike burst duration. Both during the fasted and fed states the occurrence of the spike burst was restricted to a limited segment of the slow wave cycle. Within this segment, however, the spike burst began or ended at any time. Spike burst onset $\overrightarrow{\bar{\sigma}}$ delay and spike burst cycle duration differed significantly $(p<0.05)$ between phase 3 , phase 2 , and the fed state; for these states, spike burst onset delay was $0.77 \pm 0.01, \quad 0.87 \pm 0.01$, and $0.98 \pm 0.03$ respectively, whereas spike burst cycle duration was $3 \cdot 24 \pm 0 \cdot 06,3 \cdot 19 \pm 0 \cdot 05$, and $3 \cdot 15 \pm 0 \cdot 04$ respectively. Spike burst duration was greater $(\mathrm{p}<0.05)$ in phase 3 ○ $(0.74 \pm 0.04)$ than in phase $2(0.37 \pm 0 \cdot 02)$, but there was no significant difference 윽 between the latter value and that in the fed state $(0 \cdot 35 \pm 0 \cdot 02)$.

These results are consistent with the hypothesis of a control of spiking activity $\widetilde{N}$ by the slow waves. They suggest that the $N$ precise location of the spike burst as well as the slow wave period are dependent on $\omega$ factors which act differently during the fasted and fed states.

\section{2}

Effect of posture on glucose absorption and insulin secretion after different types of vagotomy

R BITTNER, R LUDWIG, AND H G BEgER ( $U l m$, Germany) The reports concerning the $ᄋ$ effects of posture on gastric emptying and oral glucose tolerance in patients after 
vagotomy and even in normal persons are quite contradictory. For further clarification of the influence of the posture on oral glucose tolerance and insulin secretion three groups of patients were tested twice (on two different days): (1) 12 healthy volunteers; (2) 15 patients after selective gastric vagotomy with Finney-pyloroplasty. On the first day the patients received a liquid test meal (BSD, $80 \mathrm{~g}$ carbohydrates) in a sitting position and on a second day the meal was taken in the supine position. Before and after the meal plasma glucose and insulin concentrations were measured over a three hour test period.

It was concluded that: (1) in the controls as well as in the HSV-patients both the pattern of glucose curve and the insulin secretion are not affected by the posture (except the glucose-lows). (2) In the patients with selective gastric vagotomy + Finney-pyloroplasty the posture has a significant effect on all the five criteria measured. (3) In the selective gastric vagotomy + Finney-pyloroplasty patients when in the sitting position the most impressive fact is that the insulin peak is extremely high. Whereas in the control patients, there is a significant correlation between the rise of glucose and the insulin peak $(r=0.7)$ as well as between the glucose peak and the insulin peak $(r=0.87)$, in the selective gastric vagotomy + Finney-pyloroplasty patients we could not find any relationship between glucose pattern and this high insulin response. (4) Thus, it is suggested that the high insulin in the sitting selective gastric vagotomy + Finney-pyloroplasty patients may be caused by an additional intestinal factor secreted in excess as a result of uncontrolled rapid gastric emptying of the test meal. Confirming this hypothesis the calculation of 'insulinogenic index' shows that in the selective gastric vagotomy + Finney-pyloroplasty patients when in the sitting position the insulin secretion capacity is significantly higher than in the supine position.

\section{3}

The significance of propulsive, retropulsive, and segmenting contractions of the colon and rectum in the irritable bowel syndrome

J CUMming, M J KELLY, ${ }^{*}$ AND C L SMITH $\dagger$ (London, Portsmouth, ${ }^{*}$ Southampton, ${ }^{\dagger}$ UK) Contractions of the recto-sigmoid and rectum were detected in a control group $(n=8)$ and an irritable bowel group $(n=23)$ by the use of a new detecting device using strain gauges attached to a polyvinyl tube. Recordings were performed over a 45 minute period in a fasting state followed by a further 45 minutes after subcutaneous injection of $0.6 \mathrm{mg}$ neostigmine.

Three types of contractions were identified $(A, B, C)$ with respect to the configuration and duration of wave length. Propagated contractions were identified by their sequential time difference between the three strain gauge tracings and propulsive, retropulsive, and segmenting contractions were recorded.

There was no significant difference between the two groups in the incidence of types of contraction, propagated or segmented contractions, direction of spread or rate of spread. Where the irritable bowel patients were symptomatic at the time of recording, however, this was associated with a highly significant incidence of segmenting contractions which tended to be of the $\mathrm{C}$ contraction type. Significantly, more B contractions were propagated than C contractions which tended to be segmenting but some were noticed to be propagated.

This study suggests that there is no intrinsic motor abnormality in the irritable bowel syndrome but an abnormality is identified when the patient is suffering from symptoms.

\section{4}

Manometry of the sigmoid colon in the irritable bowel syndrome

F BALDI, $R$ CORINALDESI, F FERRARINI, $M$ CASSAN, G BRUNETTI, AND L BARBARA (Bologna, Italy) Motility of the sigmoid in the irritable bowel syndrome has been extensively studied, with contrasting results.

In 11 irritable bowel syndrome patients (eight women, mean age 40.4 years, range 22-56 years) and in six age and sex matched controls we evaluated sigmoid motility by manometry and gastrointestinal transit time by an ingested radioisotopic capsule. In the patients we also assessed frequency and severity of abdominal pain episodes and bowel movement frequency.

The results show the motility index was similar both in basal conditions and after prostigmine $0.5 \mathrm{mg}$ intramuscularly in the two groups. Linear regression analysis showed no correlation between frequency, severity, and bowel movement frequency on one hand and percentage duration of motor activity and mean wave amplitude on the other, whereas the transit times, both total and of the left colon, correlated significantly with both motor indices recorded at $25 \mathrm{~cm}$ after prostigmine $(r=0 \cdot 66-0 \cdot 80)$. The patients with total transit time greater than the upper value of the controls had a motility index greater than that of the patients whose total transit time fell within normal range (17-64 hours) $(33 \cdot 83 \pm 15 \cdot 5$ vs $64 \cdot 9 \pm 37 \cdot 2)$. Manometry of the sigmoid does not differentiate our irritable bowel syndrome patients from the controls; the motor response to a mild cholinergic stimulus correlates in these patients with transit time but not with symptoms.

\section{5}

A new technique for recording and analysing colorectal myoelectric activity

J A A ARCHBOLD, T G PARKS, AND A E WALBRIDGE (Belfast, UK) Recognisable patterns of myoelectric activity have been shown in the colorectal region of patients suffering from irritable bowel syndrome and colonic diverticular disease.

This communication describes the use of the Oxford medilog system to record the myoelectric activity of the large intestine. A suction electrode is placed via a sigmoidoscope at the rectosigmoid junction and the signal fed to a medilog recorder. The cassette is later replayed at 25 times the recording speed and sampled by a PDP11/ 34 computer and the digitised results stored on a floppy-disc. Analysis of the data is performed interactively to questions displayed on the visual display unit. A suitable section of data is selected for fast Fourier transformation analysis and the results displayed on the visual display unit or X-Y plotter.

Using this method we have been able to show the preponderance of slow wave activity in the 2-4 cpm range in irritable bowel syndrome and slow wave activity in the $12-18 \mathrm{cpm}$ range in diverticular disease.

The equipment used is readily available and is inexpensive and simple to use. The recording system is portable and can be used in any clinical situation. Analysis can be carried out immediately or at a later date using standard computing equipment.

56

Pressure-volume relationships in the rectum. A comparative study in normal and constipated children 
P MEUNIER (Lvon, France) Recordings of pressure curves in function of rectal distending volumes have been performed in 31 control subjects (mean age $8 \pm 2.8$ years) and in 63 primarily constipated patients (mean age $8 \pm 3 \cdot($ ) years), 44 of whom were encopretics.

The method consisted of the recording of the pressure in a rectal balloon mounted on a two-channel catheter. One channel was used for continuous pressure measurement, while the other channel was used to inflate incrementally the rectal balloon with air. From the actual pressure-volume curve three parameters were derived: (1) the maximal rectal tolerable volume, (2) the maximal rectal tolerable pressure, and (3) the maximal rectal compliance.

As an analysis of variance showed no significant difference for the three parameters between sexes and age classes, results in control and constipated children were compared without taking account of sex and age.

Compared with controls, the constipated children showed significantly $(p<0.001)$ higher mean values for maximal rectal tolerable volume $(376 \pm 167 \cdot 7$ vs $188 \pm 143.6$ $\mathrm{ml})$ and maximal rectal compliance $(81 \pm 52.4$ vs $27 \pm 7 \cdot 2 \mathrm{ml} / \mathrm{KPa})$, but there was no significant difference between mean values for maximal rectal compliance $(6 \pm 2 \cdot 1$ vs $7 \pm 1.6 \mathrm{ml} / \mathrm{KPa})$.

Maximal rectal tolerable pressure was abnormal in $18 \%$ of the patients. maximal rectal tolerable volume was abnormal in $68 \%$ of the constipated patients, maximal rectal compliance was abnormal in $72 \%$ of the patients. Only $22 \%$ of the constipated patients proved to have all three parameters within the normal range.

Thus, a large majority of patients exhibited an abnormal pressure-volume relationship, and an increase of encopresis incidence was observed in children with high maximal rectal tolerable volume and/ or maximal rectal compliance.

57

Rectal function after mucosal proctectomy with ileo-anal anastomosis or a pelvic reservoir for ulcerative colitis

D E NEAL, N S WILLIAMS. AND D JOHNSTON (Leeds, UK) Mucosal proctectomy with either ileo-anal anastomosis or construction of a pelvic reservoir has been used to preserve continence in the treatment of ulcerative colitis. There is little information on the physiology of such patients. Therefore, patients undergoing such procedures have been studied prospectively by rectal manometry and EMG. Before operation, all $(n=21)$ had severe proctitis with low capacity $(101+52$ $\mathrm{ml})$ and compliance $\left(2+2 \mathrm{ml} / \mathrm{cm} \mathrm{H}_{2} \mathrm{O}\right)$ and shown inhibition of the internal sphincter and EMG facilitation during distension. After operation, there was a decrease in anal canal pressure $(p<0 \cdot 01)$ and in the number of patients with inhibition of the internal sphincter $(p<0 \cdot 01)$. The pressure within the neo-rectum to facilitate EMG activity was greater after operation $(p<0 \cdot 05)$. The capacity and compliance, both early after and more than one year later was greater in the pelvic reservoir than ileo-anal anastomosis $(p<0 \cdot 01)$. There was significant improvement in both over the subsequent months.

Patients without a rectal stricture were continent. At a mean follow up of $1 \cdot 3$ years $(n=14)$, the frequency of defaecation was less in pelvic reservoir (4/day) than in ileo-anal anastomosis $(6 \cdot 5 /$ day $)$. At present a pelvic reservoir appears to give better functional and physiological results than ileo-anal anastomosis in adults.

\section{8}

Effect of a transpyloric tube on gastric emptying and duodenogastric reflux in man and dog

S A MÜLLER-LISSNER, C J FIMMEL, G SCHATTENMANN, J R SIEWERT, AND A L BLUM (München, Germany, and Zürich, Switzerland) The effect of transpyloric tube on gastric emptying and duodenogastric reflux was studied in six healthy volunteers and in 10 dogs. The dogs either had an intact pylorus (five), a Heineke-Mikulicz pyloroplasty (two), or an extramucosal circular pylorectomy (three). After instillation of a liquid lipid meal, gastric volumes were measured at 10 minute intervals for 120 minutes by a marker dilution technique using ${ }^{51} \mathrm{Cr}$ and ${ }^{58} \mathrm{Co}$, respectively, and the rate of gastric emptying was calculated. Duodenogastric reflux was measured simultaneously by methods which do not require a transpyloric tube. The duodenal marker in man was ${ }^{99} \mathrm{~m} \mathrm{Tc}-\mathrm{HIDA}$ which is excreted by the liver and enters the duodenum via the bile. Its amount appearing in the stomach was determined from the gastric samples and expressed as fraction of its intraduodenal amount as determined by gamma-camera measurements. In dogs, the duodenal marker $\left({ }^{57} \mathrm{Co}\right)$ was infused via a duodenal fistula.
Duodenogastric reflux was calculated from the concentrations of ${ }^{57} \mathrm{Co}$ in gastric and duodenal samples. Duodenogastric reflux was also measured in the fasting state both in man and in dogs. All experiments were done in the presence and absence, respectively, of a transpyloric tube (outside diameter $5 \mathrm{~mm}$ ). Duodenogastric reflux in man was similar in the fasting state and after feeding and was not affected by a transpyloric tube. In fed dogs with circular pylorectomy, gastric emptying, duodenogastric reflux, and gastric accumulation of duodenal juice were higher than in dogs with an intact pylorus but a transpyloric tube had no additional effect. In fasting dogs, reflux was on the average four times higher with a tube than without $(p<0.001)$ and was on the average 10 times smaller than after a meal $(\mathrm{p}<0.005)$.

In conclusion, a transpyloric tube does not affect gastric emptying and postprandial duodenogastric reflux in man and dog, and fasting reflux in man. Reflux may be augmented by a transpyloric tube under conditions with a very low reflux rate such as in the fasting dog.

59

Does the human pylorus close in response to an isolated duodenal cap contraction? Studies with a new technique

A G JOHNSON, G E LINHARD, I EYRE-BROOK, AND R H SMALLWOOD (Sheffield, UK) Although during gastric emptying, the pylorus closes with a terminal antral contraction, the key question for the prevention of duodenogastric reflux is whether the pylorus closes in response to a duodenal contraction when the antrum is $ᄋ$ relaxed.

We have studied the timing of pyloric $\frac{T}{O}$ closure using four silver wire electrodes $6 \equiv$ $\mathrm{mm}$ long mounted around the circumfer- $\mathrm{N}$ ence of a Fogarty catheter ( $5 \mathrm{FG}, 1 \cdot 1 \mathrm{~mm} \mathrm{~N}$ diameter) just proximal to the balloon. N Impedance between opposite pairs of $\omega$ electrodes is measured at $100 \mathrm{kHz}$ using a current of $100 \mu \mathrm{A}$. Pyloric closure is registered when all four electrodes are $\Phi$ touched by the pyloric ring. The device is passed down the ACMI twin-channel $T$ gastroscope and positioned with the balloon just in the duodenum maintaining the electrode in the pyloric canal; a second $\frac{C}{\mathbb{D}}$ Fogarty balloon, passed down the second $\varrho$ biopsy channel records terminal antral contractions.

Eleven consenting patients who were음 found at routine endoscopy (under 
diazepam alone) to be free of structural gastroduodenal disease were studied for 10 minutes in the fasting state. In $85 \%$ of 92 isolated (unlinked) duodenal contractions the pylorus closed in response to the duodenal contraction. The pylorus probably prevents reflux by closing when an isolated duodenal cap contraction occurs.

60

Antral contractions and fluid movement in the human stomach. Observations with real time ultrasound

R D ADAM, W N MCDICKEN, T ANDERSON, AND R C HEADING (Edinburgh, UK) We have shown previously that ultrasonic techniques can provide detailed imaging of the fluid filled stomach and can permit the study of the relationships between movements of the stomach wall and luminal contents under physiological conditions with no discomfort or risk to the subject.

Our observations indicate that in normal subjects, episodes of caudad movement, retrograde movement, and no movement of the luminal contents through the pylorus occur within the duration of a single gastric peristaltic cycle - that is, while the contraction wave is moving steadily down the stomach. Retrograde movement has been observed at some time in every subject and was particularly striking immediately after episodes of marked caudad movement through the pylorus lasting three to six seconds. Such episodes did not occur during every peristaltic cycle.

In one normal subject, a sequence of retrograde gastric peristalsis was observed on two separate occasions. Each time, three consecutive waves of contraction were seen to migrate from distal to proximal antrum; normally propagated contractions resumed thereafter. During one such wave of retrograde peristalsis, marked caudad movement of gastric contents through the pylorus were seen to occur.

These observations indicate firstly that brief episodes of retrograde gastric peristalsis may occur in a normal healthy subject, and secondly that the movement of gastric contents through the pylorus cannot be satisfactorily explained in terms of a steadily advancing wave of gastric peristalsis.

\section{1}

Manometric and electromyographic studies of the sphincter of Oddi in man

M BORTOLOTTI, G C CALETTI, E BROCCHI, S FOSCHI, A LONGANESI, G GUIZZARDI, AND G LABÒ (Bologna, Italy) This study was carried out in 18 patients referred for diagnostic ERCP in whom morphology was found to be normal. Eight were asyptomatic $(\mathrm{N})$, six had recurrent biliary pain without stones after previous cholecystectomy $(\mathrm{C})$, and four had undergone sphincterotomy (S). Manometric changes were recorded through a side-hole Tefion catheter, perfused with water at $0.2 \mathrm{ml} / \mathrm{min}$ with an Arndorfer pump, and connected to a pressure transducer and polygraph. In five of the $\mathrm{N}$ group and three of the $\mathrm{C}$ group, myoelectric activity was recorded at the same time from a pair of $\mathrm{Ag}-\mathrm{AgCl}$ electrodes protruding from the probe adjacent to the side-hole and connected to an AC amplifier (time constant 0.03 second) in the polygraph. Duodenal pressure was recorded through a catheter taped to the endoscope and was taken as the zero reference pressure. After diazepam sedation and sphincter of Oddi cannulation, the probe was withdrawn in 1 mm steps from the CBD through the sphincter of Oddi, where there was a high pressure zone with superimposed phasic pressure waves and rhythmic spike bursts. Results were expressed as mean $\pm \mathrm{SE}$ $\mathrm{mm} / \mathrm{Hg}$. Both $\mathrm{C}$ and $\mathrm{S}$ patients differed significantly from $\mathrm{N}$ (control patients) in terms of high pressure zone $(\mathrm{N}=27 \pm 2$, $\mathrm{C}=49 \pm 13, \mathrm{~S}=8 \cdot 8$ ), phasic pressure waves $(\mathrm{N}=100 \pm 8, \mathrm{C}=152 \pm 15, \mathrm{~S}=28 \pm 7)$, and CBD tone $(\mathrm{N}=19 \pm 0.8, \mathrm{C}=35 \pm 5$, $S=4 \cdot 9 \pm 2 \cdot 8)$.

In the $\mathrm{N}$ group, spike bursts corresponded with the ascending phase of phasic pressure waves, and their duration (1-3 seconds) and mean amplitude $(0 \cdot 3$ $\mathrm{mV}$ ) were proportional to those of phasic pressure waves. In the $\mathrm{C}$ group, with hyperactivity of the sphincter of Oddi, duration and amplitude of spike bursts was greater than in the $\mathrm{N}$ group.

It is concluded that (1) in some patients, recurrent biliary pain in the absence of gall stones may be because of a hypertonic sphincter of Oddi; (2) sphincterotomy reduces the high pressure zone, and this technique can be used to control its extent; (3) this preliminary EMG study suggests that electromyography gives results broadly comparable with manometry while avoiding the potential hazard of intraductal perfusion and, with two or more electrode pairs, can show the direction of phasic pressure waves propagation across the sphincter. 